NASA TECHNICAL MEMORANDUM 104105

\title{
ANALYSIS OF THERMOMECHANICAL FATIGUE OF UNIDIRECTIONAL TITANIUM METAL MATRIX COMPOSITES
}

M. Mirdamadi, W. S. Johnson, Y. A. Bahei-El-Din, and M. G. Castelli

Presented at the ASTM Symposlum on Composites Materials:

Fatigue and Fracture IV, Indlanapolis, Indlana, May 6-9, 1991

\section{JULY 1991}

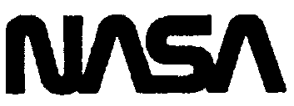

National Aeronautics and

Space Administration

Langley Research Center

Hampton, Virginia 23665

(NASA-TM-104105) ANALYSIS OF

THERMOMECHANICAL FATICUE OF UNIOIRECTIONAL

THERMOMECHANICAL MATKIX COMPOSITES (NASA) 
- . -

•

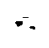


ANALYSIS OF THERMOMECHANICAL FATIGUE OF UNIDIRECTIONAL TITANIUM METAL MATRIX COMPOSITES

M. Mirdamadi ${ }^{1}$, W. S. Johnson ${ }^{2}$, Y. A. Bahei-El-Din ${ }^{3}$, and M. G. Castelli4

Thermomechanical fatigue (TMF) data has been generated for a Ti-15V-3Cr-3Al-3Sn (Ti-15-3) material reinforced with SCS-6 silicon carbide fibers for both in-phase and out-of-phase thermomechanical cycling. Significant differences in failure mechanisms and fatigue life were noted for in-phase and out-of-phase testing. The purpose of the research reported in this paper is to apply a micromechanics model to the analysis of the data. The analysis predicts the stresses in the fiber and the matrix during the thermal and mechanical cycling by calculating both the thermal and mechanical stresses and their rate-dependent behavior. The rate-dependent behavior of the matrix was characterized and was used to calculate the constituent stresses in the composite. The predicted $0^{\circ}$ fiber stress range was used to explain the composite failure. It was found that for a given condition, temperature, loading frequency and time at temperature, the $0^{\circ}$ fiber stress range may control the fatigue life of the unidirectional composite.

KEY WORDS: silicon-carbide fibers, isothermal fatigue, stress range, interface, residual stresses, in-phase, out-of-phase, nonisothermal.

1-National Research Council Research Associate, NASA Langley Research Center, Mail Stop 188E, Hampton, VA 23665-5225. 2-Senior Scientist, NASA Langley Research Center, Mail stop 188E, Hampton, VA 23665-5225.

3-Research Associate Professor, Department of Civil Engineering, Rensselaer Polytechnic Institute, Troy, NY 12180. On leave from Cairo University, Giza, Egypt.

4-Research Engineer, Sverdrup Technology, Inc., NASA Lewis

Research Center, Mail Stop 49-7, Cleveland, Ohio 44135. 


\section{SYMBOLS}

$A, A^{*}, n, n^{*}$
$E$
$H$
$k, p$
$R$
$S$
$S_{\min }$
$S_{\max }$
$T$
$\dot{\epsilon}$
$\dot{\epsilon}$
$\dot{\epsilon}$
$\dot{\epsilon}$ in
$\alpha$
$\Delta o_{f}$

Curve fitting constants

Young's modulus

overstress

Temperature-dependent experimentally determined parameters

Stress ratio $\left(S_{\min } / S_{\max }\right)$

Composite stress

Minimum stress

Maximum stress

Temperature

Strain rate

Thermal strain rate

Elastic strain rate

Inelastic strain rate

coefficient of thermal expansion

Fiber stress range

\section{INTRODUCTION}

Titanium matrix composites, such as $\mathrm{Ti}-15 \mathrm{~V}-3 \mathrm{Cr}-3 \mathrm{Al}-3 \mathrm{Sn}$ (Ti-15-3) reinforced with continuous silicon carbide (SCS-6) fibers, are being considered for use on hypersonic aerospace vehicles. The structural materials in such vehicles require high temperature capability, light weight, and high stiffness. However, due to the significant difference in the coefficient of thermal expansion (CTE) of the fiber and matrix, cyclic stresses and strains are produced in the fiber and matrix whenever the temperature is cycled. Thermal cycling could result in internal damage which may effect the macromechanical behavior of the composite. Furthermore, at temperatures above $480^{\circ} \mathrm{C}$, the titanium matrix exhibits thermo-viscoplastic behavior. since projected operating temperatures are expected to be well into the creep range, the rate-dependent behavior of the matrix material must be considered in the thermomechanical fatigue (TMF) evaluation of the composite behavior.

The objectives of this research are (1) to use an analytical method that was developed under contract with NASA Langley Research center to evaluate TMF and nonisothermal fatigue data of unidirectional SCS-6/Ti-15-3 composites under in-phase and out-of-phase loading and (2) to determine the critical constituent stresses (strains) that control laminate fatigue behavior under TMF and nonisothermal fatigue loading, taking into account the rate-dependent behavior of the matrix. The constitutive equations of a unidirectional ply are defined using the vanishing fiber diameter (VFD) model [1]; these constitutive equations are then used in a laminated plate analysis to model a laminate [2]. The constitutive behavior of the matrix is described with a thermo-viscoplastic model developed by Bahei-El-Din, et al. [3]. Among some of the recent work on the fatigue of scs-6/Ti-15-3, Johnson, et al. [4] and Pollock and Johnson [5] 
studied the static isothermal tensile behavior and isothermal fatigue behavior of a variety of layups at room temperature and at an elevated temperature of $650^{\circ} \mathrm{C}$. These laminates were made with fugitive binders. The composite used in the room temperature research [4] was in the "as-fabricated" condition. The laminates used in the $650^{\circ} \mathrm{C}$ tests [5] were aged for one hour at $650^{\circ} \mathrm{C}$ in air prior to testing. All layups had a fiber volume fraction of 0.325 . The isothermal fatigue tests were conducted under load control at $10 \mathrm{~Hz}$ with an $\mathrm{R}$ ratio $\left(\mathrm{S}_{\min } / \mathrm{S}_{\max }\right)$ of 0.1 . At room temperature, fatigue failure was observed in the fibers but not in the matrix, except for one long-life test. It was suggested that the $0^{\circ}$ plies played a dominant role in controlling fatigue life. In particular, the authors suggested that the stress range in the $0^{\circ}$ fibers controlled life. They showed that the room temperature fatigue data of several layups could be collapsed to a narrow band when plotted as a function of the stress range in the 00 fiber, as shown in Figure 1. At $650^{\circ} \mathrm{C}$, Pollock and Johnson [5] observed that a high cyclic strain resulted in a short life due to multiple fiber failure with no matrix fatigue cracking. On the other hand, low cyclic strains resulted in long lives with extensive matrix cracking prior to fiber failure. Thus, the cyclic life of the composite at $650^{\circ} \mathrm{C}$ was also governed by the cyclic stress range in the $0^{\circ}$ fibers; however, more scatter was found in the $0^{\circ}$ fiber stress range at $650^{\circ} \mathrm{C}$ than was found in the room temperature data.

Castelli, et al. [6] studied the TMF behavior of a 9-ply unidirectional SCS-6/Ti-15-3 laminate in a temperature range of $93^{\circ} \mathrm{C}$ to $538^{\circ} \mathrm{C}$. The TMF tests were conducted under load control with $R=0.05$ and a cycle time of 180 seconds. The composites used in their study were fabricated from matrix foil and plies of unidirectional Sic fibers held in place by fugitive binders and had a fiber volume fraction of 0.34 . The composite was aged at $700^{\circ} \mathrm{C}$ for 24 hours in an argon environment prior to testing. Castelli observed that TMF greatly reduced cyclic fatigue lives when compared with isothermal and in-phase nonisothermal data. The failure modes under TMF test conditions were significantly different from those observed under comparable isothermal test conditions. Out-of-phase TMF loadings displayed a matrix dominated failure, where cracking and crack initiation sites were found entirely at surface and near-surface locations. In-phase TMF loadings resulted in ductile matrix failure and fiber pull-out across the entire fracture surface, with extensive fiber breakage in the absence of matrix cracking.

Isothermal and in-phase and out-of-phase load-controlled nonisothermal fatigue experiments were performed by Gabb, et al. [7] on a unidirectional SCS $-6 / \mathrm{Ti}-15-3$ composite between $300^{\circ} \mathrm{C}$ and $550^{\circ} \mathrm{C}$. The composite sheets used in their study were fabricated from matrix foil and plies of unidirectional sic fibers held in place by $\mathrm{Ti}-6 \mathrm{Al}-4 \mathrm{~V}$ weaving. Unlike the true TMF tests where the load and the temperature are cycled simultaneously, in the nonisothermal tests the load was cycled at a constant temperature followed by a temperature cycle at zero load. The fatigue test cycles used by Gabb are shown in Figure 2. Under in-phase loading 
conditions, the load was cycled to a maximum at the maximum temperature of $550^{\circ} \mathrm{C}$, followed by a thermal cycle from $550^{\circ} \mathrm{C}$ to $300^{\circ} \mathrm{C}$ at zero load. Under out-of-phase loading conditions, the load was cycled to a maximum at the minimum temperature of $300^{\circ} \mathrm{C}$, followed by a thermal cycle from $300^{\circ} \mathrm{C}$ to $550^{\circ} \mathrm{C}$ at zero load. Gabb found that, based on the cyclic stress range, both in-phase and out-of-phase nonisothermal fatigue lives were shorter than the isothermal fatigue lives at $300^{\circ} \mathrm{C}$ and $550^{\circ} \mathrm{C}$.

\section{ANALYTICAL METHOD - VISCOPLY}

The VISCOPLY code developed by Bahei-El-Din is a micromechanics analysis based on constituent properties. The program combines the vanishing fiber diameter (VFD) model [2], a thermo-viscoplastic theory [3], and laminated plate theory to evaluate the rate-dependent, high temperature response of symmetric fibrous composite laminates. The viscoplastic theory models isotropic materials, where fiber and matrix are characterized individually, and both can be viscoplastic. The VFD model accounts for the orthotropic behavior. The VISCOPLY program accepts any combination of thermal and mechanical loads. The mechanical loads consist of in-plane axial stress or strain rates, in-plane transverse stress rate, in-plane shear stress rate, and out-of-plane normal stress rate. The program can run sequential jobs which allows any order and rate of load and temperature. The program computes fiber and matrix stresses and strains and the overall composite response under thermomechanical loading conditions, and can simulate fabrication and actual tests performed on composite specimens.

The viscoplastic theory used in the VISCOPLY program was developed by Bahei-El-Din, et al. [3] for high temperature, nonisothermal applications. The theory reduces to the formulation given by Eisenberg and Yen [9] at low temperatures and is itherma] conditions. The theory used in VISCOPLY assumes that the elastic response is rate-independent and that inelastic strains develop when the current stress point lies outside an equilibriun yie?d surface. When the material is subjected to quasi-static loading, the yield surface may harden kinematically and isotropically, causing the stress point to fall on the yield surface. The inelastic strain in this case can be found with a rate-independent plasticity theory. The quasi-static stress-strain curve is referred to as the equilibrium curve and corresponds to the theoretical lower bound of the dynamic response. If the material is loaded at a finite stress or strain rate and the yield stress is exceeded, the stress point may fall outside the initial yield surface. The inelastic strain rate is described using a power law function of the overstress $H$ which is defined as the difference between the current stress and the equilibrium stress.

The total strain rate is given by [3] as the sum of the elastic strain rate, $\dot{e}$, thermal strain rate, $\dot{\epsilon}$, and the inelastic strain rate, $\dot{\epsilon}$. Under uniaxial loading, the strain rate is given by: 


$$
\begin{gathered}
\dot{\epsilon}=\dot{\epsilon}+\dot{\epsilon}+\dot{\epsilon} \mathrm{in} \\
=\dot{\sigma} / \mathrm{E}(\mathrm{T})+\mathrm{m}(\mathrm{T}) \dot{\mathrm{T}}+\mathrm{k}(\mathrm{T}) \mathrm{H}^{\mathrm{p}}(\mathrm{T})
\end{gathered}
$$

where $m(T)=\alpha(T)-\left(\sigma / E^{2}(T)\right) d E(T) / d T$, and

$$
\mathbf{H}=\boldsymbol{\sigma}-\boldsymbol{o}^{*}
$$

Here $\mathrm{E}$ is Young's elastic modulus, $\mathrm{T}$ is the temperature, $\alpha$ is the coefficient of thermal expansion, $\sigma^{*}$ is the equilibrium stress defined by the quasi-static stress-strain curve.

The parameters $k$ and $p$ in $\mathrm{Eq}$. (1) must be determined experimentally and are temperature dependent. When isotropic hardening and thermal recovery effects are not significant, these parameters can be found from two monotonic uniaxial tests. However, if isotropic hardening and thermal recovery effects are significant, the behavior becomes more complex, and evaluation of the quasi-static curve more difficult [3]. In the present paper, we determine the material parameters $k$ and $p$ assuming isotropic hardening and thermal recovery effects are negligible for the Ti-15-3 matrix. Determination of the material parameters $k$ and $p$ will be presented in the experimental section of this paper. The fiber was assumed to be isotropic and remain elastic although the model has the capability to model the fiber as a viscoplastic material with transverse orthotropic properties. Loss of composite stiffness as a result of matrix cracking may be approximated by reducing the modulus of the matrix in the model.

\section{MATERIAL AND EXPERIMENTAL PROCEDURE}

In order to analyze the TMF data using the thermo-viscoplastic model [3] several material parameters were required. Strain-controlled and load-controlled tests at specific temperatures and loading rates were conducted to evaluate the necessary material parameters. Previously generated test data was also used to validate the model.

\section{Material}

The Ti-15-3 matrix material is a metastable beta strip alloy. The alloy is weldable, ageable, and relatively insensitive to corrosive environments [8]. Long exposures at elevated temperatures can lead to the precipitation of an alpha phase, which may alter the macroscopic behavior of the material [8]. Therefore, the material in the present study was subjected to a heat treatment prior to testing. The matrix alloy was obtained in a $500 \times 500 \times 5-\mathrm{mm}$ panel and cut into specimens 5-mm thick, 13-mm wide and 152-mm long. The specimens could be subjected to desired test loads without buckling. The specimens were heat treated at $650^{\circ} \mathrm{C}$ for one hour followed by an air quench. This heat treatment was based on Differential scanning Calorimetry (DSC) tests conducted 
by Pollock and Johnson [5]. The DSC measures the heat flow into a sample as a function of time. Since the heat flow varies with metallurgical instabilities such as phase changes, it was used to determine the time necessary to reach a steady state heat flow during an isothermal hold.

\section{Test Procedures}

The tests necessary to determine the equilibrium curves and the material parameters $k$ and $p$ were conducted in a $100 \mathrm{kN}$ servo-hydraulic test frame with water-cooled grips. The specimens were heated using a $5 \mathrm{~kW}$ induction generator. The temperature distribution along the gage section of the specimen was measured with six thermocouples (three on each face of the specimen, measured from center, $15 \mathrm{~mm}$ apart on one face and $20 \mathrm{~mm}$ apart on the other face). The induction coil was adjusted to minimize the temperature gradient within the gage section to a differential of less than $10^{\circ} \mathrm{C}$. In all tests, the temperature of each specimen was monitored and controlled with a K-type thermocouple spot welded to the center of the specimen and a microprocessor controlled induction generator. Axial strains were measured on the edge of the specimen by a high temperature, water-cooled extensometer with a 25-mm gage length. The strain-controlled tests used to determine the equilibrium curves were conducted with a strain rate of $1 \times 10^{-4} \mathrm{~mm} / \mathrm{mm}$ per second. The load-controlled monotonic tests used to determine $k$ and $p$ were conducted at $a$ constant rate of $2.56 \mathrm{MPa}$ per second. These rates were representative of loading rates expected in actual service conditions. Tests were recorded on a $X-Y$ plotter and a strip chart recorder. Material property data was determined at the following temperatures: room temperature, $316^{\circ} \mathrm{C}, 482^{\circ} \mathrm{C}, 566^{\circ} \mathrm{C}$ and $650^{\circ} \mathrm{C}$. Strain-controlled tests on $\mathrm{Ti}-15-3$ showed that once the maximum stress was reached, the stress dropped (stress softening) with further straining, approaching a constant stress level. This behavior was observed consistently at strain rates between $1 \times 10^{-4}$ and $1 \times 10^{-2} \mathrm{~mm} / \mathrm{mm}$ per second when the temperature was above $316^{\circ} \mathrm{C}$. However, under cyclic straining, the cyclic stress-strain response stabilized rapidly after the first cycle. Therefore, in all tests the matrix material was initially cycled, using a fully reversed triangular waveform, four times, to stabilize the softening behavior. The strain amplitude was chosen to avoid buckling of the specimen.

To define the equilibrium curves, five minute hold periods were imposed at predetermined strain levels as illustrated in Figure 3a. The equjlibrium curve was then approximated by a power law $\left(a^{*}=A^{*}\left(c^{\text {in }}\right)^{*}\right)$ fit to the calculated values $O{ }^{\prime}$ stress and inelastic strain, using the method of least squares. The stress-control test was conducted with a constant stress rate. Given the equilibrium curve, the overstress $H$ is determined as illustrated in Figure $3 \mathrm{~b}$. The stress and inelastic strain determined from the monotonic stress-controlled tests were also fit to a power law $(\sigma=A(c$ in) $n$ ) using the method of the least squares. The resulting equation was differentiated with respect 
to time to determine the inelastic strain rate. Once $\epsilon$ in and $H$ are known, it is a simple matter to find $k$ and $p$ using a log-log plot of inelastic strain rate and corresponding overstress values as illustrated in Figure $3 \mathrm{c}$.

In the present paper, we determined the material parameters $k$ and $p$ as described above for the Ti-15-3 matrix at room temperature, $482^{\circ} \mathrm{C}, 566^{\circ} \mathrm{C}$, and $650^{\circ} \mathrm{C}$.

\section{RESULTS AND DISCUSSION}

In this section the experimental and analytical results are presented. First, the constituent properties are presented. second, the matrix and composite behavior are analyzed using VISCOPLY and compared with observed experimental behavior. Last, VISCOPLY is used to analyze the TMF data performed by Castelli et al. [6] and nonisothermal fatigue data Gabb et al. [7] and results are compared with isothermal fatigue data of Pollock and Johnson [5] and Gabb et al. [7].

\section{Constituent Properties}

The fiber properties used in this study are shown in rable 1. As mentioned, the fiber is assumed to remain elastic and to have no temperature dependence. The Ti-15-3 matrix properties were determined from tests conducted at room temperature and the elevated temperatures of $316^{\circ} \mathrm{C}, 482^{\circ} \mathrm{C}, 566^{\circ} \mathrm{C}$ and $650^{\circ} \mathrm{C}$.

Determination of the constants $k$ and $p$ at the elevated temperatures of $566^{\circ} \mathrm{C}$ and $650^{\circ} \mathrm{C}$ was easily done as described earlier. However, at room temperature and $482^{\circ} \mathrm{C}$, determination of the material constants $k$ and $p$ required some manipulation in the curve fitting of the load-controlled tests. After the initial hardening, the load-controlled $(\dot{\sigma}=2.56 \mathrm{MPa} / \mathrm{s})$ stress-strain curve approached zero slope. Thus, the calculated value of overstress $H$ was nearly constant with increasing values of the inelastic strain rate $i$ in, resulting in nonconverging values of the constants $k$ and $p$ (Figure $3 c$ ). The exponent $n$ used in the power law for the experimental data was adjusted to give reasonable values of $k$ and $p$ and still accurately $f i t$ the experimental results. At $316^{\circ} \mathrm{C}$, the stress relaxation was minimal (as in room the temperature tests) and no load-controlled test was conducted at this temperature. Therefore, the same values of $k$ and $p$ found at room temperature were used with the elastic modulus, the yield stress, and the equilibrium curve found at $316^{\circ} \mathrm{C}$. The validity of this assumption was verified using strain-controlled test results at $316^{\circ} \mathrm{C}$. The elastic constants and yield stress as a function of temperature are given in Table 2. The curve fitting parameters used for the equilibrium and overstress curves and the parameters $k$ and $p$ are also listed in Table 2 .

The equilibrium curve and the parameters $k$ and $p$ were used in VISCOPLY to reconstruct the load-controled stress-strain curve for 
the matrix. Figures 4 and 5 show the best fit approximation of the experimental results. VISCOPLY was used to predict the stress relaxation of the matrix at $482^{\circ} \mathrm{C}$ and $650^{\circ} \mathrm{C}$. Figure 6 compares the prediction and experimental results for $650^{\circ} \mathrm{C}$. The prediction and the observed experimental behavior agree well at $650^{\circ} \mathrm{C}$. Figure 7 compares the prediction and experimental results at $482^{\circ} \mathrm{C}$. Poor agreement between the prediction and the experimental data was found at this temperature. The discrepancy between the prediction and the experiment may be attributed to isotropic hardening and thermal recovery effects which are not accounted for in the constitutive model implemented in VISCOPLY.

Laminate Behavior

The constituent properties given in Tables 1 and 2 were used to predict the laminate behavior for the isothermal tests conducted in [5]. Figure 8 compares the first cycle of an experimental stress-strain curve for a [0]8 laminate at $650^{\circ} \mathrm{C}$ with the prediction using VISCOPLY. The loading rate was 10.34 $\mathrm{MPa} / \mathrm{sec}$. As seen in the figure, VISCOPLY captured the fundamental aspects of the loading and unloading response of the composite. Note that the analysis was based on the constituents properties only and no adjustments (e.g., reducing fiber modulus) were made to improve the predictions.

Thermomechanical Response

In this section, the TMF test conducted by castelli, et al. [6] and nonisothermal fatigue conducted by Gabb, et al. [7] were analyzed using VISCOPLY. In the analysis, the TMF and nonisothermal waveforms were cycled until the fiber stress range did not change with further cycling (the fiber stress usually stabilized within five load cycles). The results will also be compared with the isothermal fatigue data of Pollock and Tohnson [5] and Gabb, et al. [7].

Castel1i, Bartolotta, Ellis. - In-phase and out-of-phase TMF tests were conducted by Castelli et al. [6] in the temperature range of $93^{\circ} \mathrm{C}$ to $538^{\circ} \mathrm{C}$ using a sinusoidal waveform for both load and temperature with a cycle time of 180 seconds. For simplicity of computation a simplified waveform, as shown in Figure 9, was used in VISCOPLY for the analysis of the data from [6]. In-phase TMF corresponds to maximum stress at maximum temperature; out-of-phase TMF corresponds to maximum stress at minimum temperature. The fatigue lives for in-phase and out-of-phase loading, as a function of the applied maximum stress $s_{\text {max }}$ are shown in Figure 10. The TMF lives under in-phase loading conditions were considerably shorter than those under out-of-phase loading conditions.

The VISCOPLY program was used to analyze the observed difference in TMF lives. Predictions were made using the constituent properties given in Tables 1 and 2 . The fiber properties given in Table 1 were assumed to waln constant 
throughout the TMF cycle. The matrix properties were assumed to be the same from room temperature to $150^{\circ} \mathrm{C}$. It was assumed that any residual stresses that developed during the fabrication of the composites would be relieved due to relaxation at absolute temperatures greater than one half of the melting temperature of the matrix [10]. Therefore, a temperature change of $555^{\circ} \mathrm{C}$ was used to simulate the cooldown during the fabrication process. The stress-strain responses under in-phase and out-of-phase loading are shown in Figures 11 and 12 , respectively. Also shown in the Figures 11 and 12 are the VISCOPLY predictions. Under in-phase loading TMF conditions the VISCOPLY predicted the creep ratcheting behavior of the composite. For the out-of-phase TMF loading VISCOPLY predicted an almost elastic response which was not found experimentally; however, the minimum and maximum strains were predicted accurately.

Figure 13 shows the predicted stresses in the fiber and matrix in a TMF cycle under in-phase and out-of-phase loading. As shown in the figure, under in-phase loading the peak stress in the fiber is higher than for the out-of-phase loading. These predictions are consistent with the fact that in the case of in-phase TMF loading, the load carrying capacity of the matrix is greatly reduced at elevated temperatures, therefore, more load is carried by the fibers than in the case of out-of-phase loading. Figure 13 also shows that the matrix stress is higher during the out-of-phase loading than during in-phase loading. This is consistent with the observations made by Castelli, et al. [6] that the specimens tested in out-of-phase loading developed extensive matrix cracking. Conversely, the in-phase loading resulted in no significant matrix cracking prior to failure.

The predicted fiber stress ratio $\left(\sigma_{\min } / \sigma_{\max }\right)$ under both in-phase and out-of-phase TMF loading conditions was 0.07 . Figure 14 shows the resulting predicted fiber stress range versus observed fatigue lives. As shown in the figure, the in-phase and out-of-phase TMF data collapsed when plotted against the fiber stress range, indicating that the $0^{\circ}$ fiber stress range apparently controls the TMF response of unidirectional composites.

As mentioned earlier, the matrix cracking can be accounted for by reducing the matrix modulus in the model. However, the change in the composite stiffness as a result of matrix cracking under out-of-phase TMF loading conditions was not throughly investigated and, therefore, the analysis was based on the initial measured elastic modulus of the matrix.

Gabb, Gayda, and MacKay. - As described previously, isothermal and nonisothermal in-phase and out-of-phase tests were conducted by Gabb, et al. [7] using the waveform shown in Figure 2. The nonisothermal in-phase and out-of-phase experimental data of Gabb, et al. [7] was analyzed using VISCOPLY. The calculated fiber stress ratio $\left(\sigma_{\min } / \sigma_{\max }\right)$ varied from 0.01 to 0.1 under in-phase loading conditions and from -0.1 to -0.05 under out-of-phase nonisothermal loading conditions. Figure 15 shows 
the observed fatigue 1 ife as a function of the predicted $0^{\circ}$ fiber stress range. As seen from the figure, the fatigue data collapsed to a narrow band indicating that fatigue failure of the unidirectional composite is apparently governed by the $0^{\circ}$ fiber stress range.

Comparisons. - The observed fatigue lives for both the Castelli, et al. [6] and Gabb, et al. [7] data are plotted as a function of the predicted $0^{\circ}$ fiber stress range in Figure 16 . As shown, the TMF and nonisothermal fatigue data from the two references separate into two bands due to the different testing conditions. The data from [6] consistently had shorter lives than data from [7]. The TMF tests conducted by Castelli, et al. [6] had a cycle time of 180 seconds, whereas nonisothermal fatigue tests conducted by Gabb, et al. [7] had a mechanical cycle time of 10 seconds followed by a thermal cycle time of 100 seconds at zero load. This may indicate that the slower frequency or more time at temperature lowers the fatigue strength of the $0^{\circ}$ fibers.

The $0^{\circ}$ fiber stress range was also used to compare the fatigue lives from the isothermal tests $[5,7]$ with the TMF [6] and nonisothermal fatigue tests [7], as shown in Figure 17. The isothermal fatigue tests of Pollock and Johnson [5] were conducted at $650^{\circ} \mathrm{C}$ with frequency of $10 \mathrm{~Hz}$ (cycle time of 0.1 seconds) and the isothermal fatigue tests of Gabb, et al. [7] were conducted at $300^{\circ} \mathrm{C}$ and $550^{\circ} \mathrm{C}$ with a frequency of 0.1 (cycle time of 10 seconds). For these isothermal tests the $0^{\circ}$ fiber stress range was calculated from the composite strain range by multiplying the strain range by the modulus of the fiber. The $0^{\circ}$ fiber stress range for the TMF, isothermal fatigue and nonisothermal fatigue conditions are shown in Figure 17. As seen in the figure, the isothermal fatigue lives were distinctly greater than and separate from the TMF and nonisothermal fatigue lives. The isothermal fatigue lives at $650^{\circ} \mathrm{C}$ with a frequency of $10 \mathrm{~Hz}$ were grester than the fatigue lives at either $300^{\circ} \mathrm{C}$ and $550^{\circ} \mathrm{C}$ with a frequency of $0.1 \mathrm{~Hz}$. However, the isothermal fatigue lives at $300^{\circ} \mathrm{C}$ were higher than those at $550^{\circ} \mathrm{C}$. Thus, for the isothermal fatigue tests at a given frequency, the higher the temperature the shorter the fatigue life. The TMF and nonisothermal tests were conducted at much lower frequencies than the isothermal tests; thus the TMF and nonisothermal fatigue specimens were exposed to high temperatures for longer periods of time. The longer exposure time at a higher temperature lowered the fatigue strength of the $0^{\circ}$ fiber. This increased exposure at elevated temperature could produce more reaction between the fiber and matrix, lowering the static strength as reported by Jeng, et al. [11] and lowering fatigue resistance as reported by Naik, Johnson and Pollock [12]. Therefore this difference in fatigue life may be more affected by length of the exposure to elevated temperature than the type of loading.

\section{CONCLUSIONS}

VISCOPLY was used to analyze the rate-dependent behavior of 
the Ti-15-3 matrix alloy. The stress-strain response of the SCS-6 fiber reinforced Ti-15-3 unidirectional composite under TMF and nonisothermal fatigue loading conditions was also predicted. The predicted $0^{\circ}$ fiber stress range was used to explain the observed fatigue behavior of unidirectional composites under isothermal, nonisothermal, and TMF loading conditions. The following conclusions were made:

- The VISCOPLY program reasonably predicted the stress relaxation of the matrix at $650^{\circ} \mathrm{C}$; however, the prediction at $482^{\circ} \mathrm{C}$ was poor. This may be due to hardening and thermal recovery which was not accounted for in the VISCOPLY code.

- The VISCOPLY program predicted the stress-strain response of the unidirectional composite under in-phase TMF loading reasonably well. In the case of the out-of-phase loading, the VISCOPLY predicted a nearly elastic stress-strain response which was not seen in the experimental data; however, the minimum and maximum strains were accurately predicted. The VISCOPLY program has proven to be a useful tool for analyzing TMF of metal matrix composites.

- Isothermal and nonisothermal fatigue data for the SCS-6/Ti-15-3 composite were analyzed using $0^{\circ}$ fiber stress range. The results indicated that the fatigue strength of the $0^{\circ}$ is controlled by a combination of temperature, loading frequency and time at temperature. Furthermore, within a given set of parameters (i.e. temperature, loading frequency and time at temperature) the stress range in the $0^{\circ}$ fiber controls fatigue life.

- Predictions were made using constituent properties only and no adjustments were made to the constituent properties to fit any specific set of experimental data. However, it may be appr priate to adjust constituent properties to account for observed damage mechanisms in the composite.

\section{ACKNOWLEDGEMENT}

The first author, M. Mirdamadi, gratefully acknowledges the support extended by the National Research Council (NRC), Washington D.C., through their Associateship program. 


\section{REFERENCES}

[1] Dvorak, G. J. and Bahei-El-Din, Y. A., "Plasticity Analysis of Fibrous Composites," Journal of Applied Mechanics, Vol. 49, 1982, pp. 327-335.

[2] Bahei-El-Din, Y. A., "Plasticity Analysis of Fibrous Composite Laminates Under Thermomechanical Loads," Thermal and Mechanical Behavior of Ceramic and Metal Matrix Composites, ASTM STP 1080, J.M. Kennedy, H.H. Moeller, and W.S. Johnson, eds., American Society for Testing and Materials, Philadelphia, 1990, pp. 20-39.

[3] Bahei-El-Din, Y. A., Shah, R. S., and Dvorak, G. J., "Numerical Analysis of the Rate-Dependent Behavior of High Temperature Fibrous Composites," Symposium on Mechanics of Composites at Elevated and Cryogenic Temperatures, ASME Applied Mechanics Division Meeting, Columbus, Ohio, June 16-19, 1991.

[4] Johnson, W. S., Lubowinski, S. L., and Highsmith, A. L., "Mechanical characterization of Unntoched SCS $_{6} / \mathrm{Ti}-15-3$ Metal Matrix Composites at Room Temperature," Thermal and Mechanical Behavior of Metal Matrix and Cermic Matrix Composites, ASTM STP 1080, J. M. Kennedy, H. H. Moeller, and $w$. S. Johnson, Eds., American Society for Testing and Materials, Phildelphia,1990, pp. 193-218.

[5] Pollock W. D and Johnson W. S., "Characterization of Unnotched SCS-6/TI-15-3 Metal Matrix Composites at $650^{\circ} \mathrm{C}$," NASA TM-102699, NASA Langley Research Center 1990.

[6] Castelli, M. G., Bartolotta, P. A., and Ellis, J.R., "Thermomechanical Fatigue Testing of High Temperature Composites: Thermomechanical Fatigue Behavior of Sic(SCS-6)/Ti-15-3," Composite Materials: Testing and Design (Tenth Volume), ASTM STP 1120, Glen C. Grimes, Ed., American Society for Testing and Materajals, Philadelphia, 1991.

[7] Gabb, T. P., Gayda, J., and MacKay R. A., "Isothermal and Nonisothermal Fatigue Behavior of a Metal Matrix Composite," Journal of Composite Materials, Vol. 24, June 1990 .

[8] Rosenberg, H, W., "Ti-15-3: A New Cold-Formable sheet Titanium Alloy, "Journal of Metals, Vol. 35, No. 11, pp. 30-34, 1986 . 
[9] Eisenberg, M. A. and Yen, C. F., "A Theory of Multiaxial Anisotropic Viscoplasticity," ASME Journal of Applied Mechanics, Vol 48, June 1981, pp. 276-284.

[10] Dieter, E. D., Mechanical Metallurgy, Second Edition, Mc Graw Hill, 1976, pp. 452-453.

[11] Jeng, S. M., Yang, C. J., Alassoeur, P. and Yang, J. M., "Deformation and Fracture Mechanisms of Fiber-Reinforced Titanium Alloy Matrix Composite," to be presented at ICCM-VIII, Honolulu, HA, 1991.

[12] Naik, R. A., Johnson, W. S., Pollock, W. D., "Effect of High Temperature Cycle on the Mechanical Properties of silicon Carbide/Titanium Metal Matrix Composites," Proceedings of the American Society for composites, Symposium on High Temperature Composites, June 13-15, 1989, pp. 94-103. 


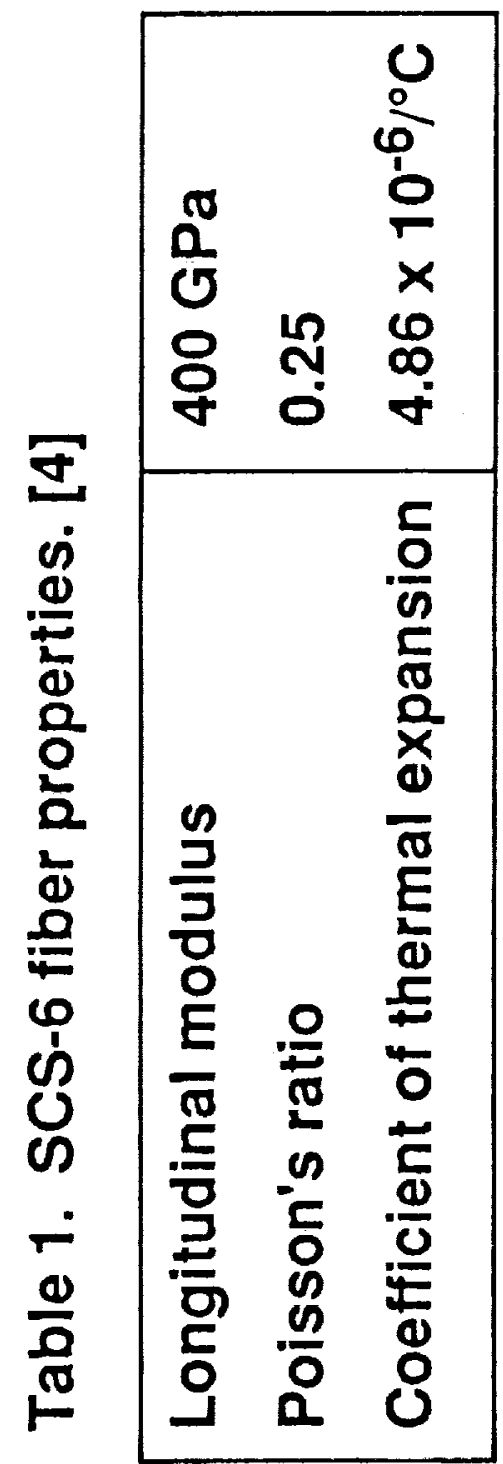




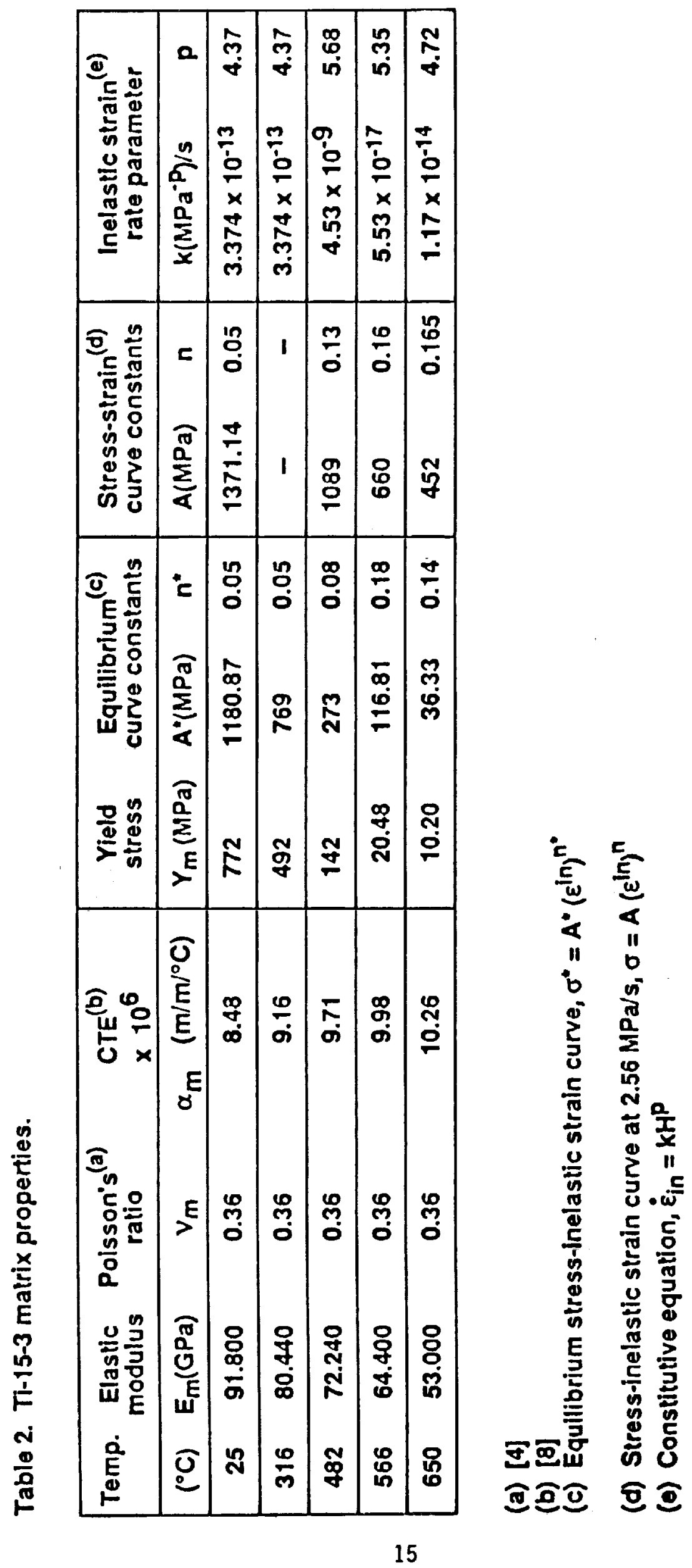




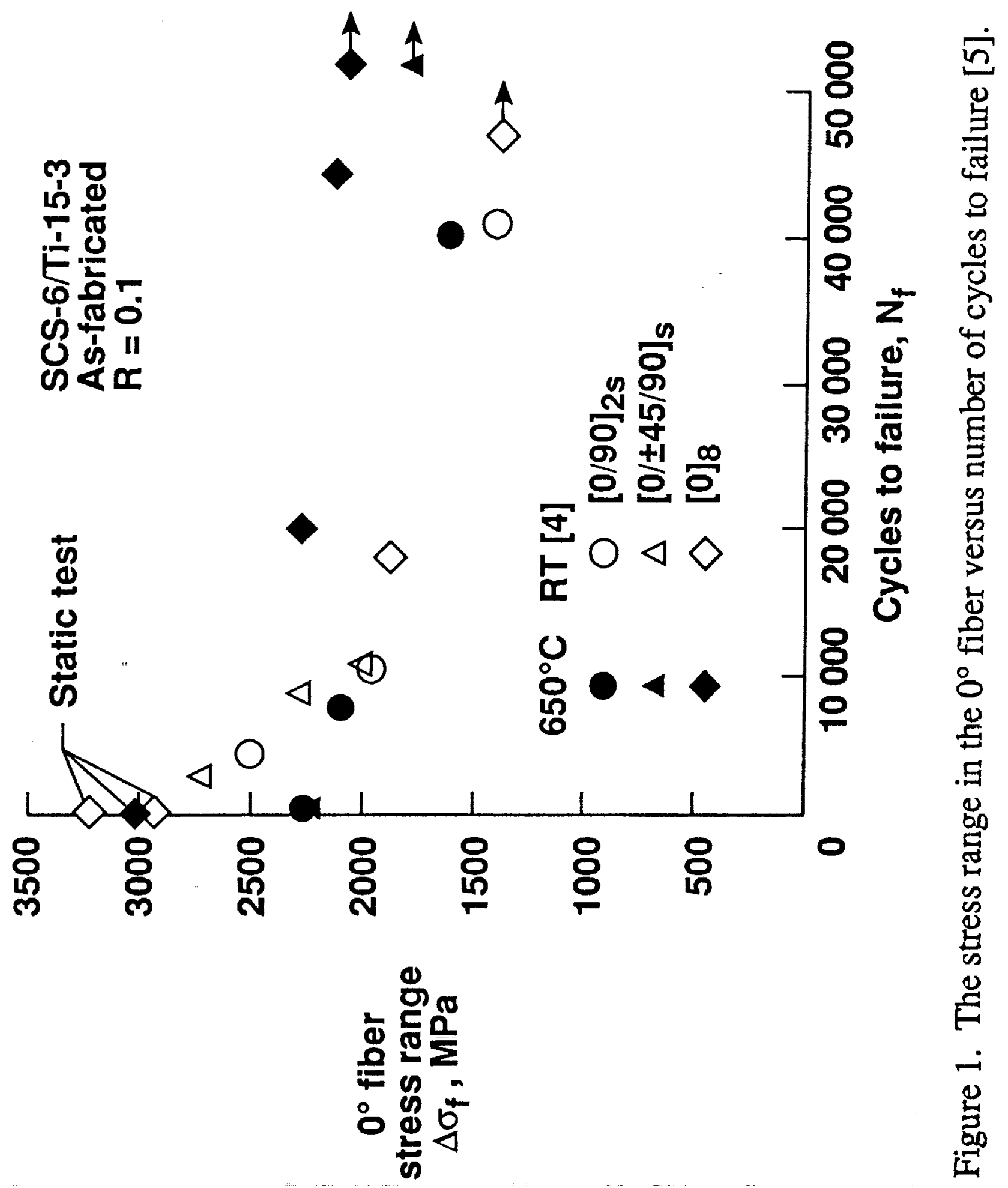



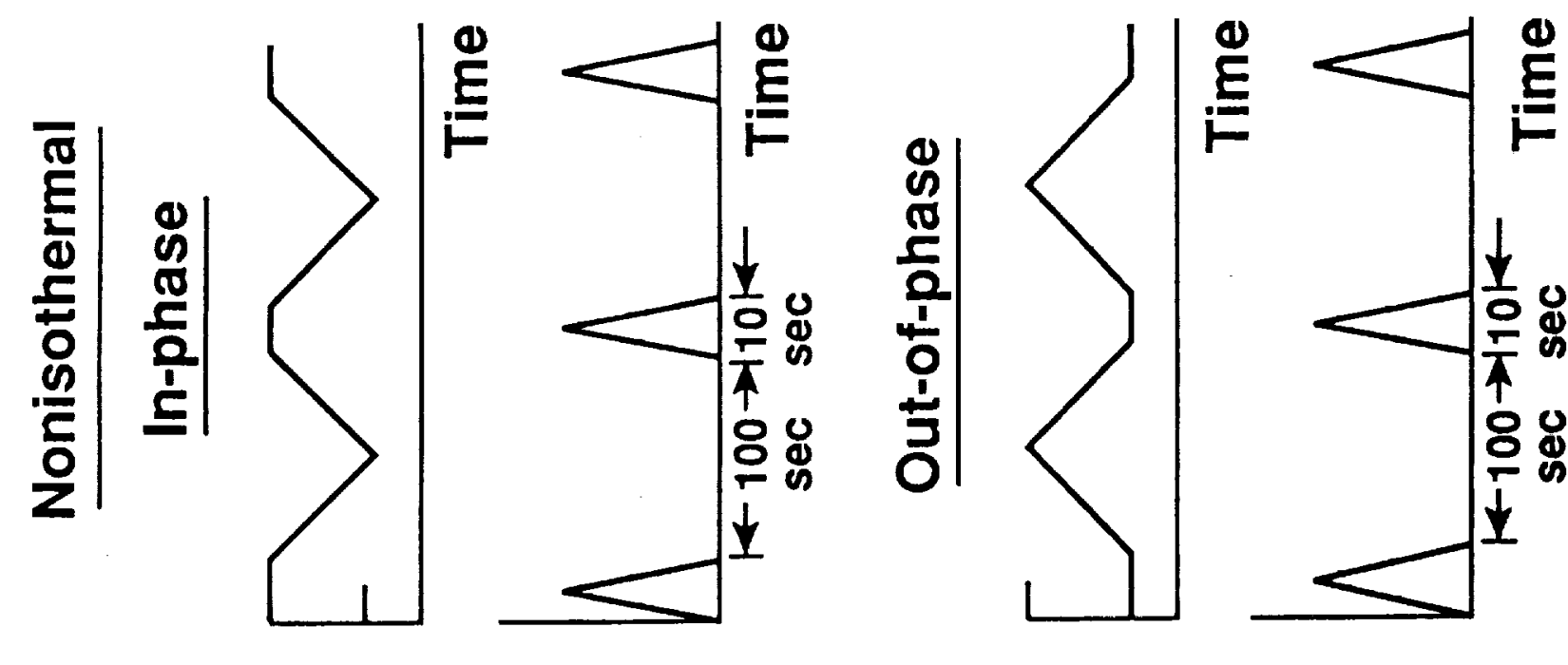

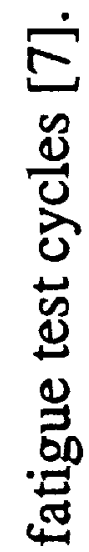

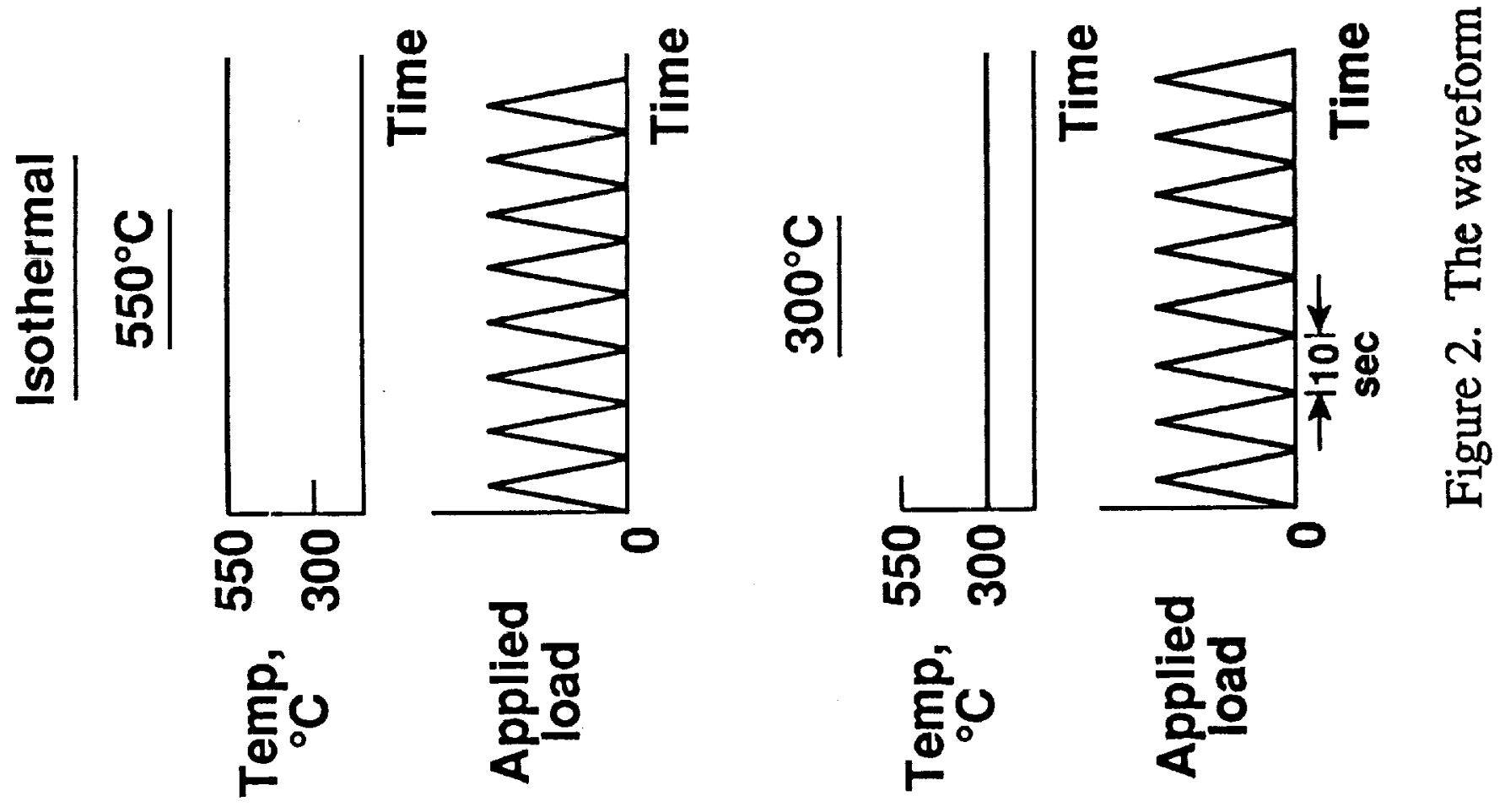




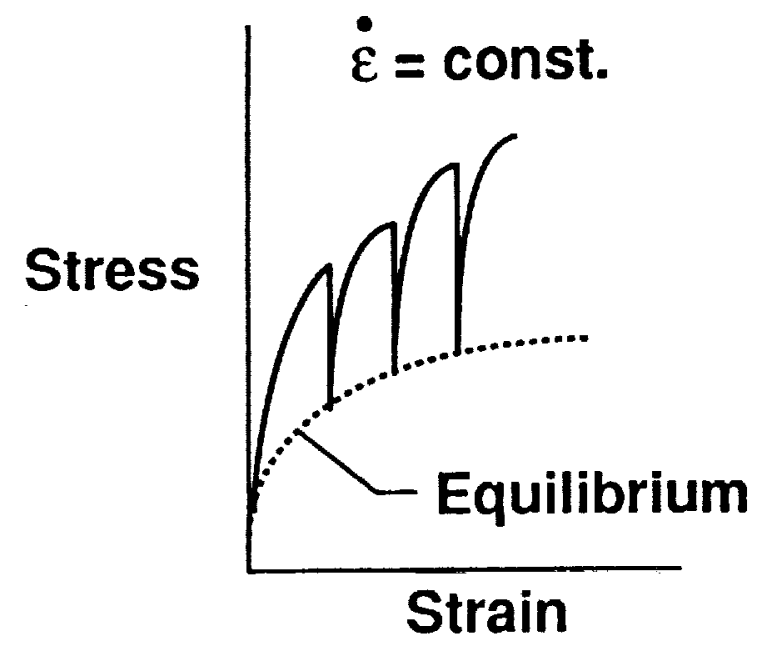

(a) Strain-controlled test

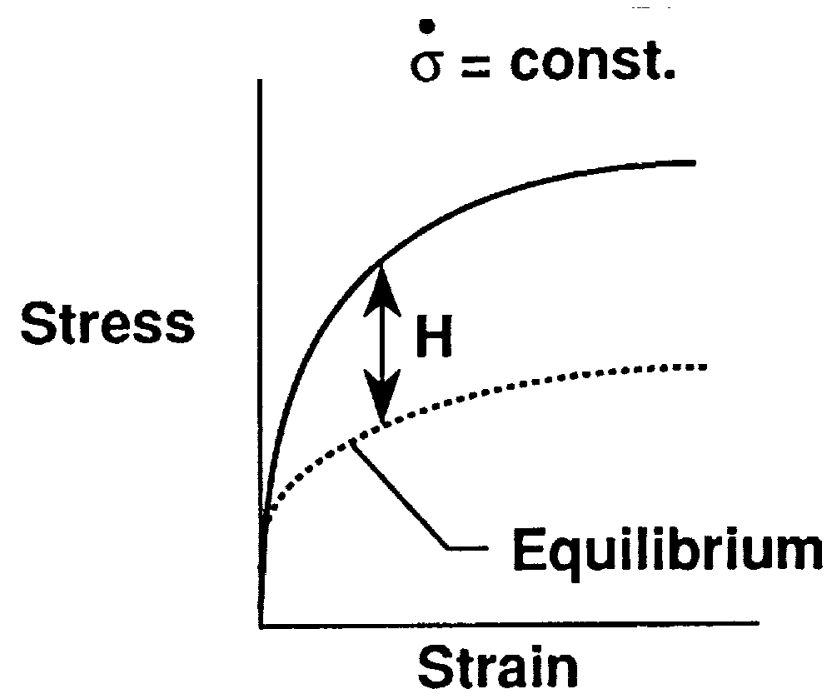

(b) Load-controlled test

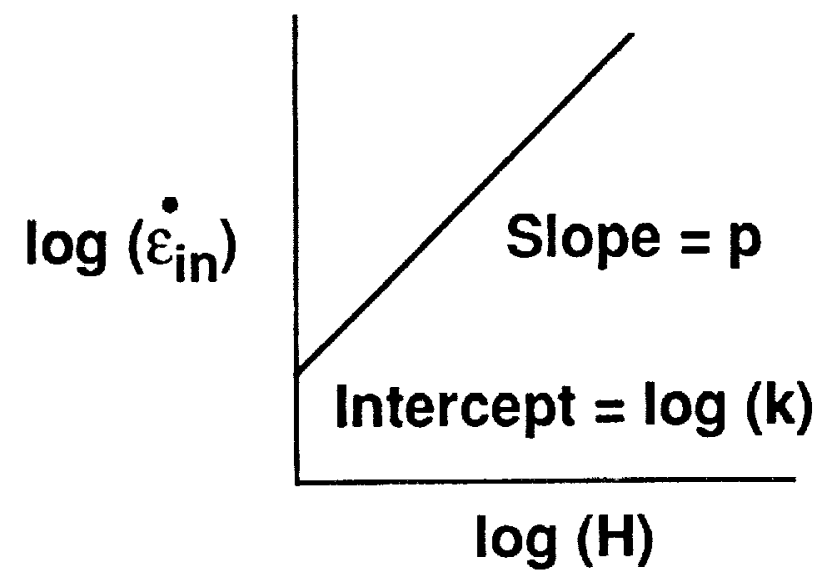

(c) Determination of $\mathrm{k}$ and $\mathrm{p}$

Figure 3. Equilibrium stress-strain curve and determination of parameters $\mathrm{k}$ and $\mathrm{p}$. 


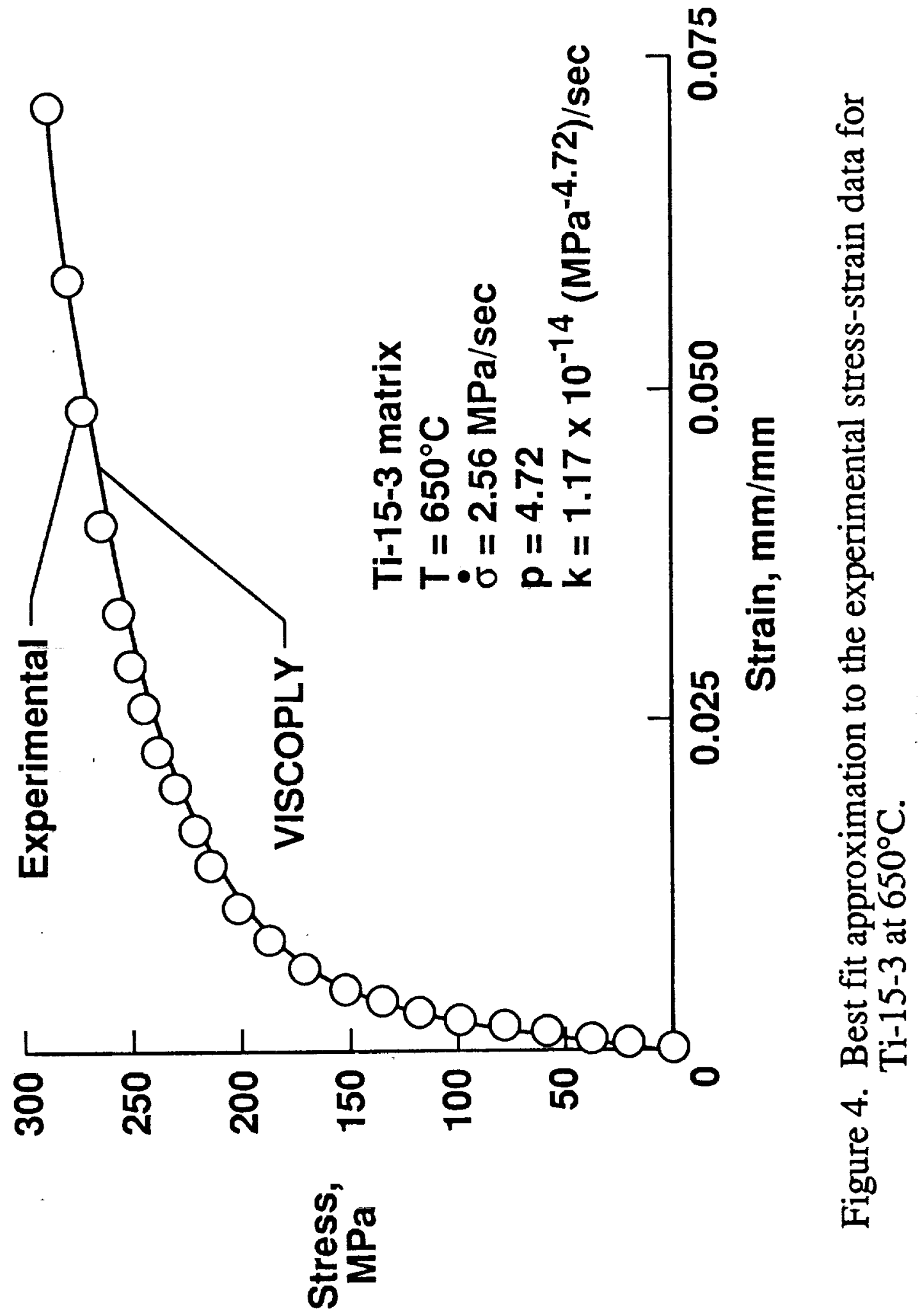




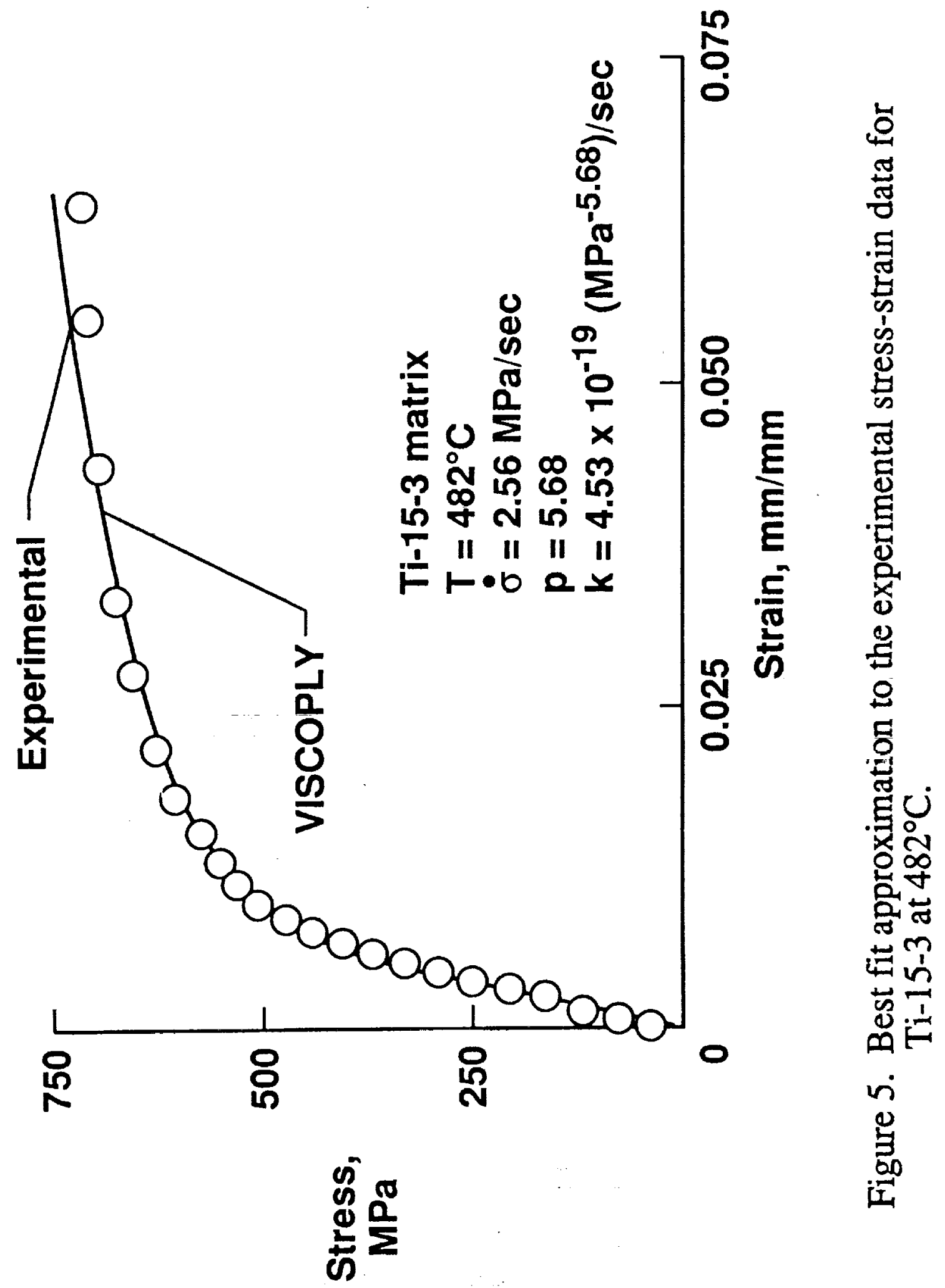




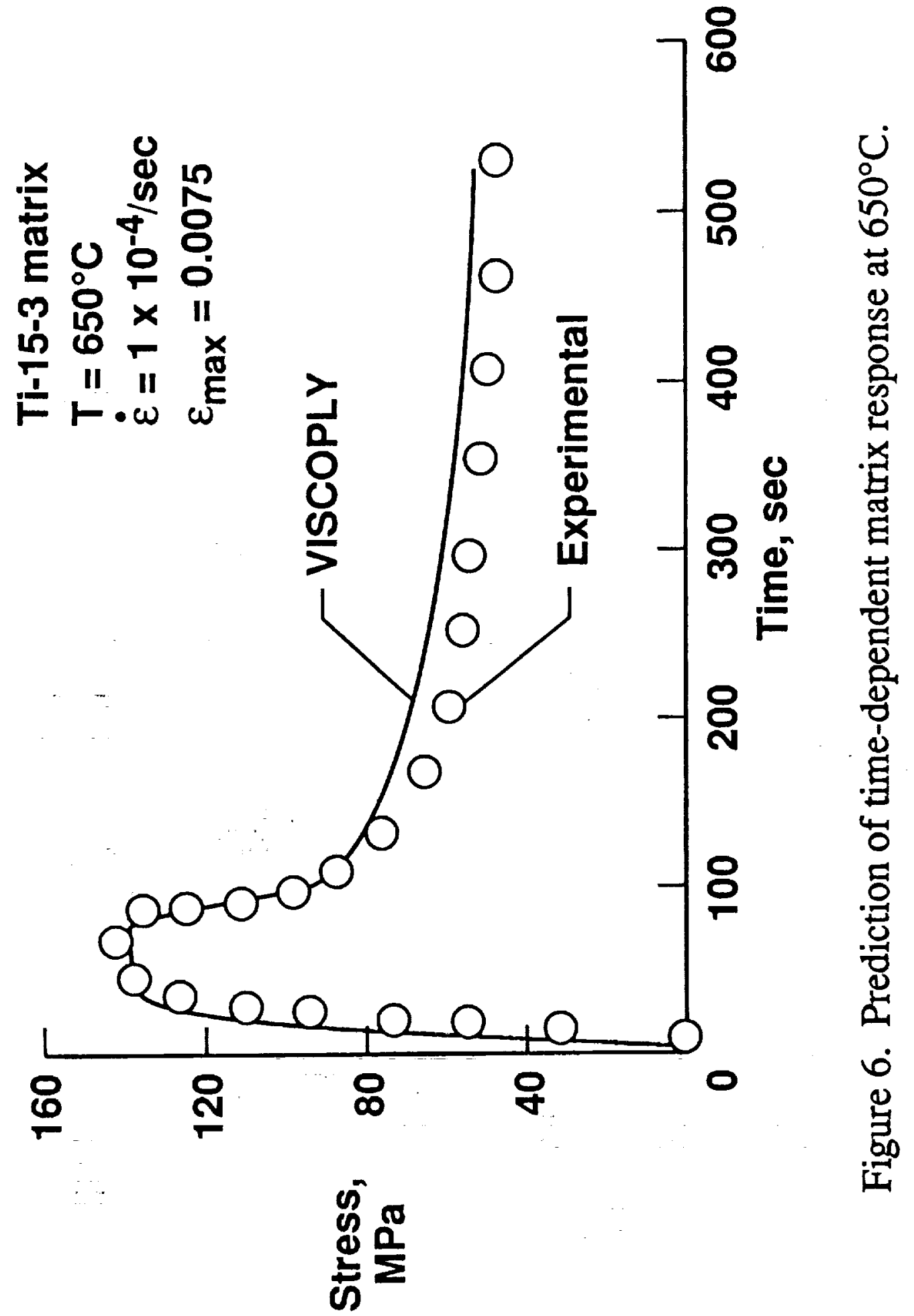




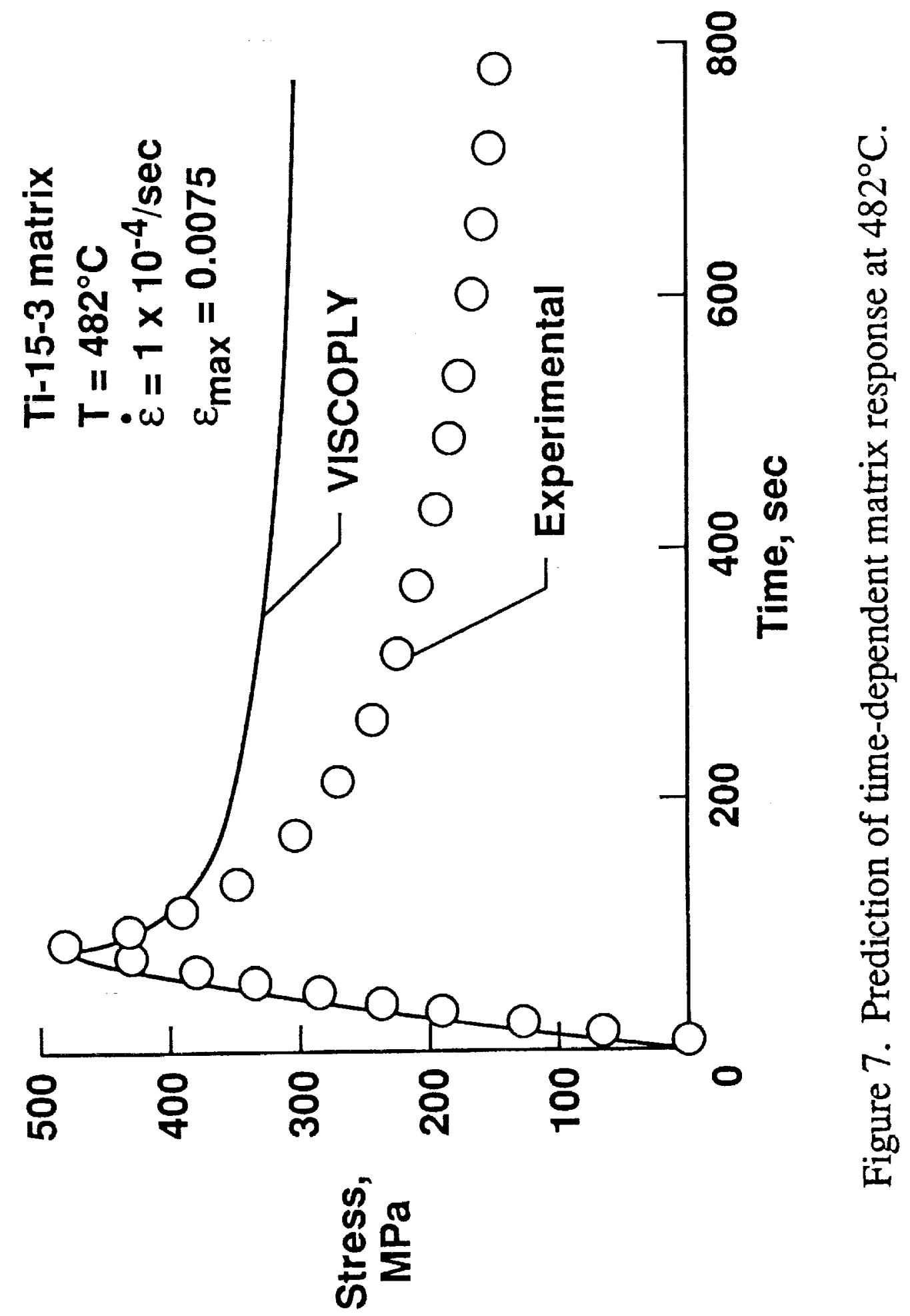




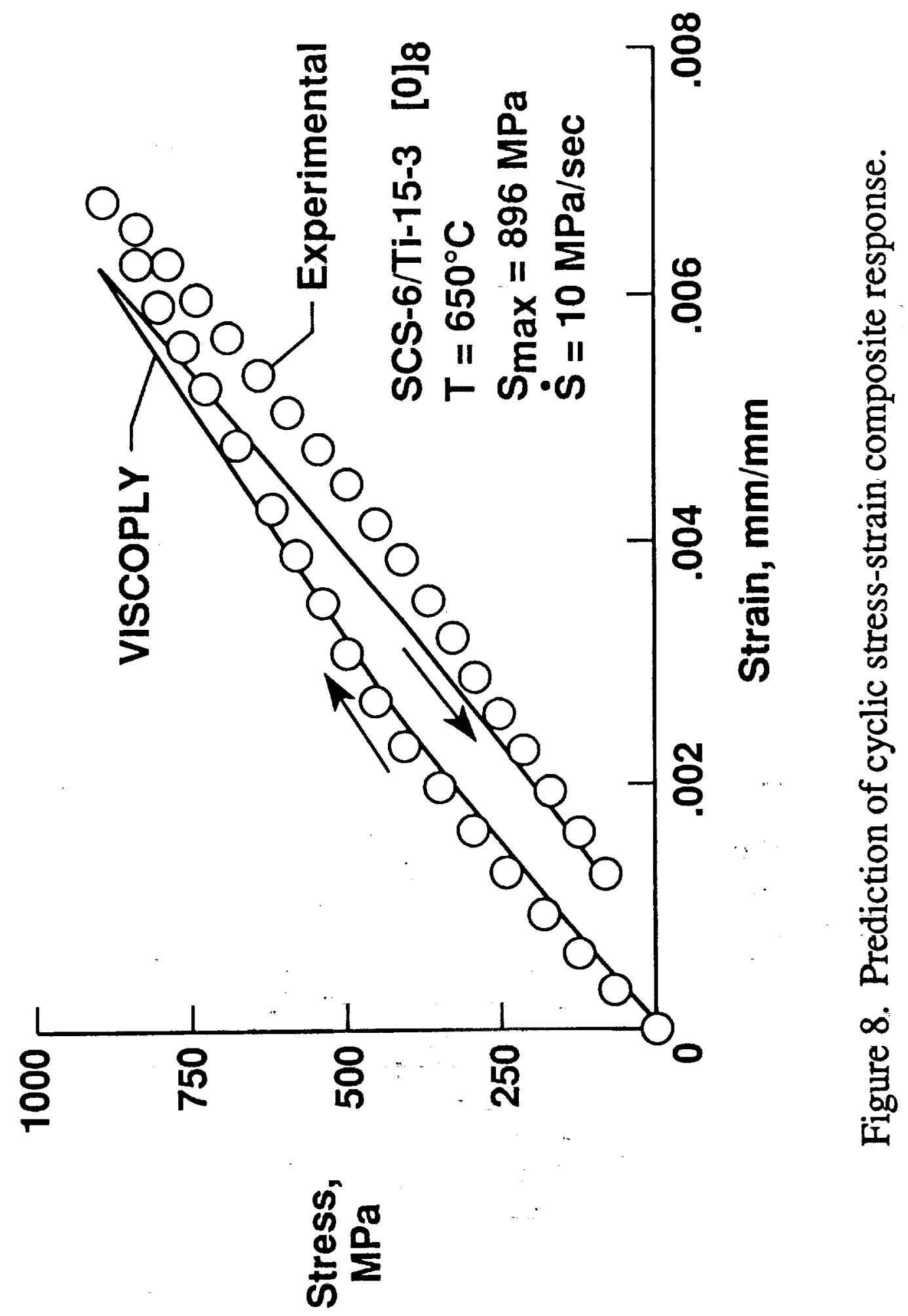


0
0
$\frac{1}{2}$
$\frac{2}{1}$
$\frac{1}{0}$
$\frac{1}{3}$
0
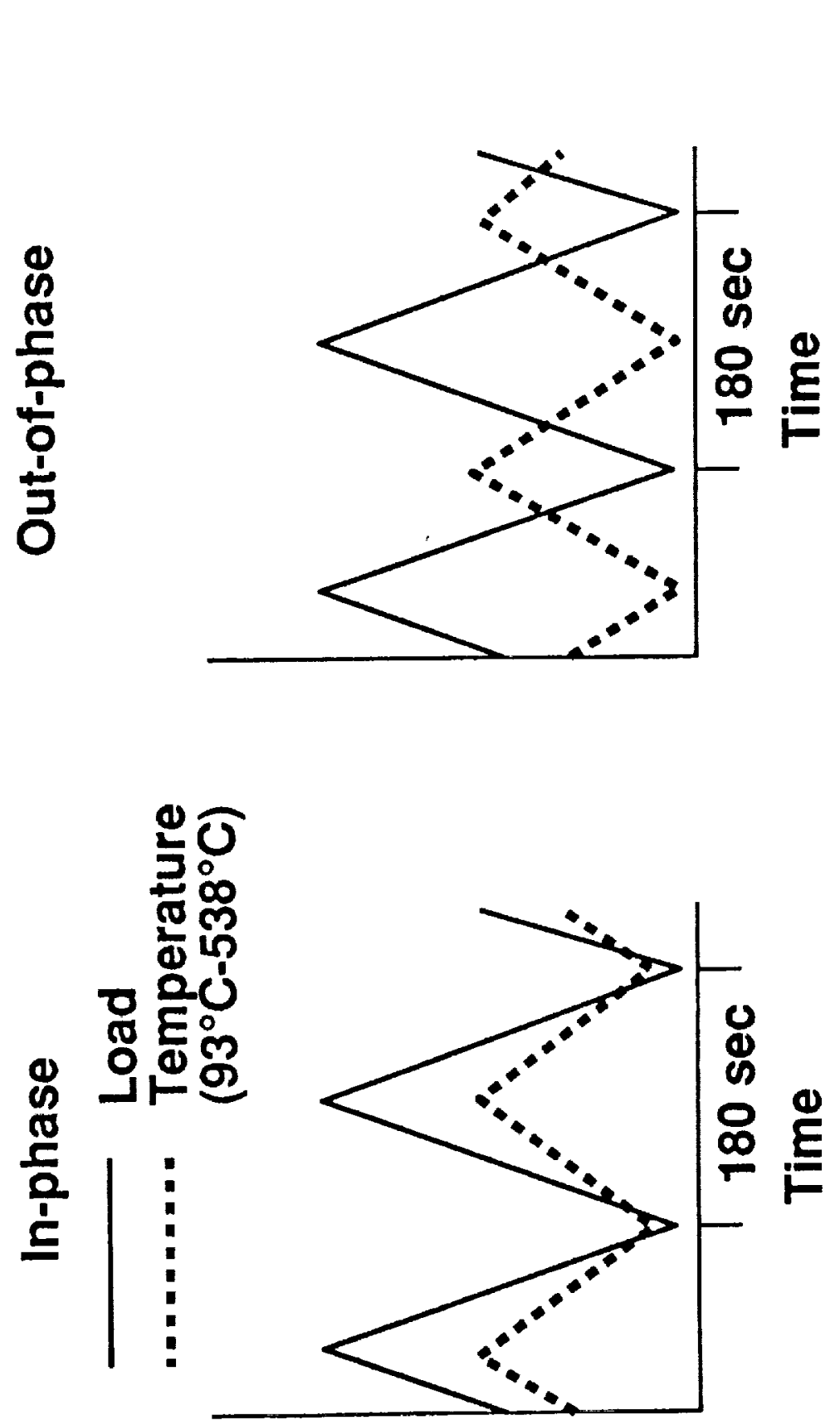

$\frac{d}{8}$

$E$

4

ह

4

$\stackrel{1}{3}$

을

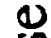

్ㅗㅇ

목

I

N

2

ह

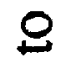

प्d

马

㤩

a

兽 


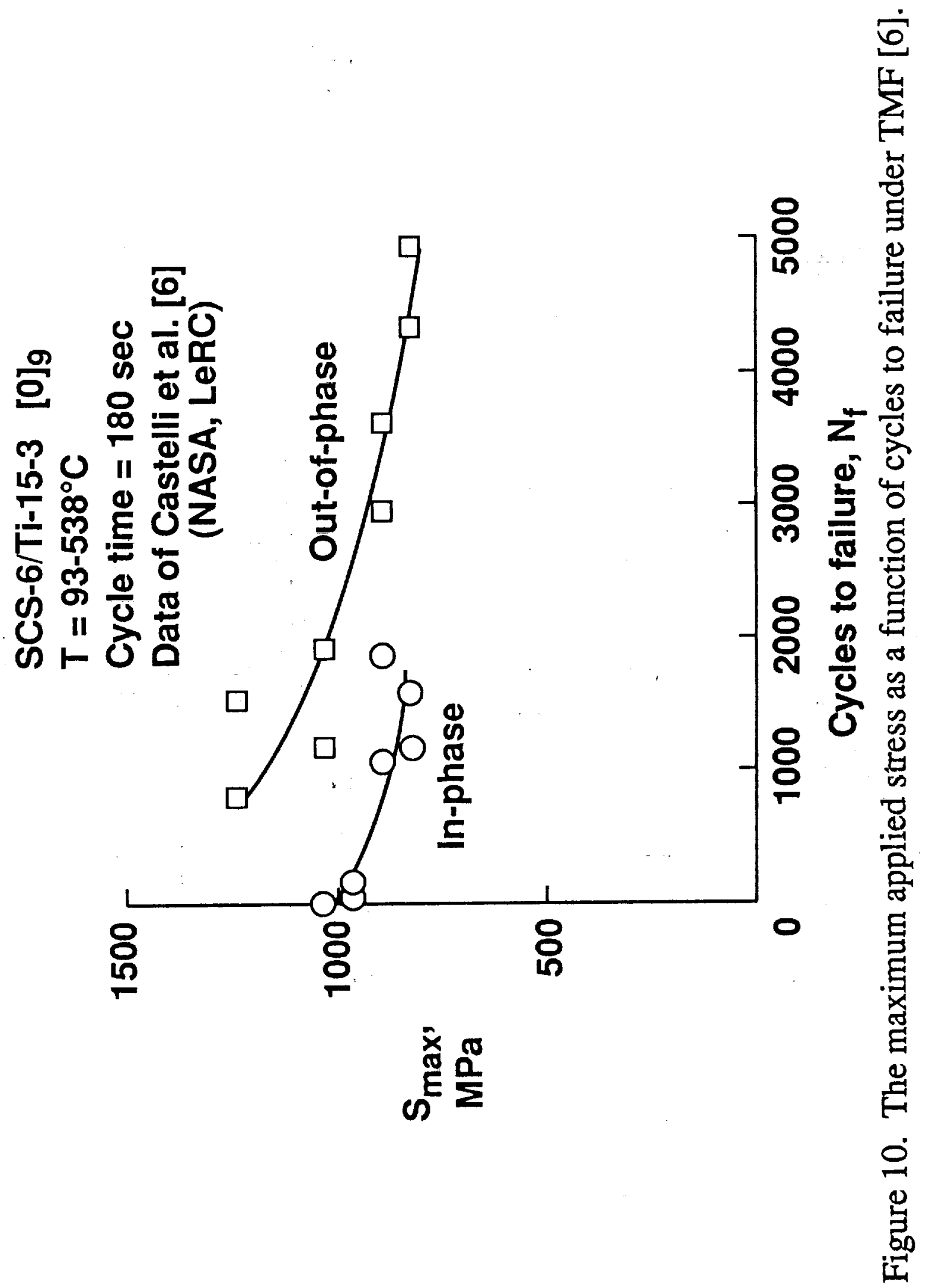




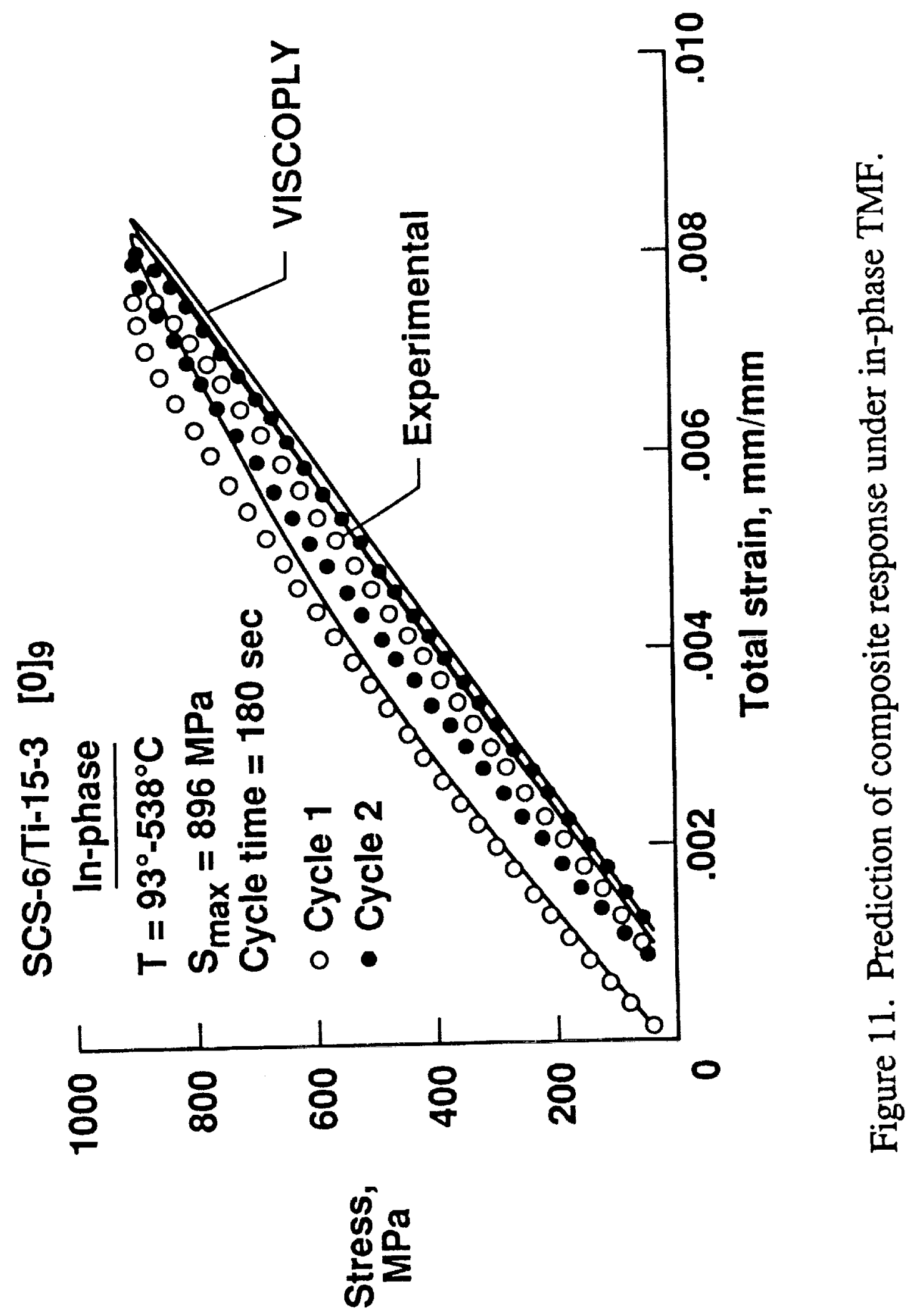




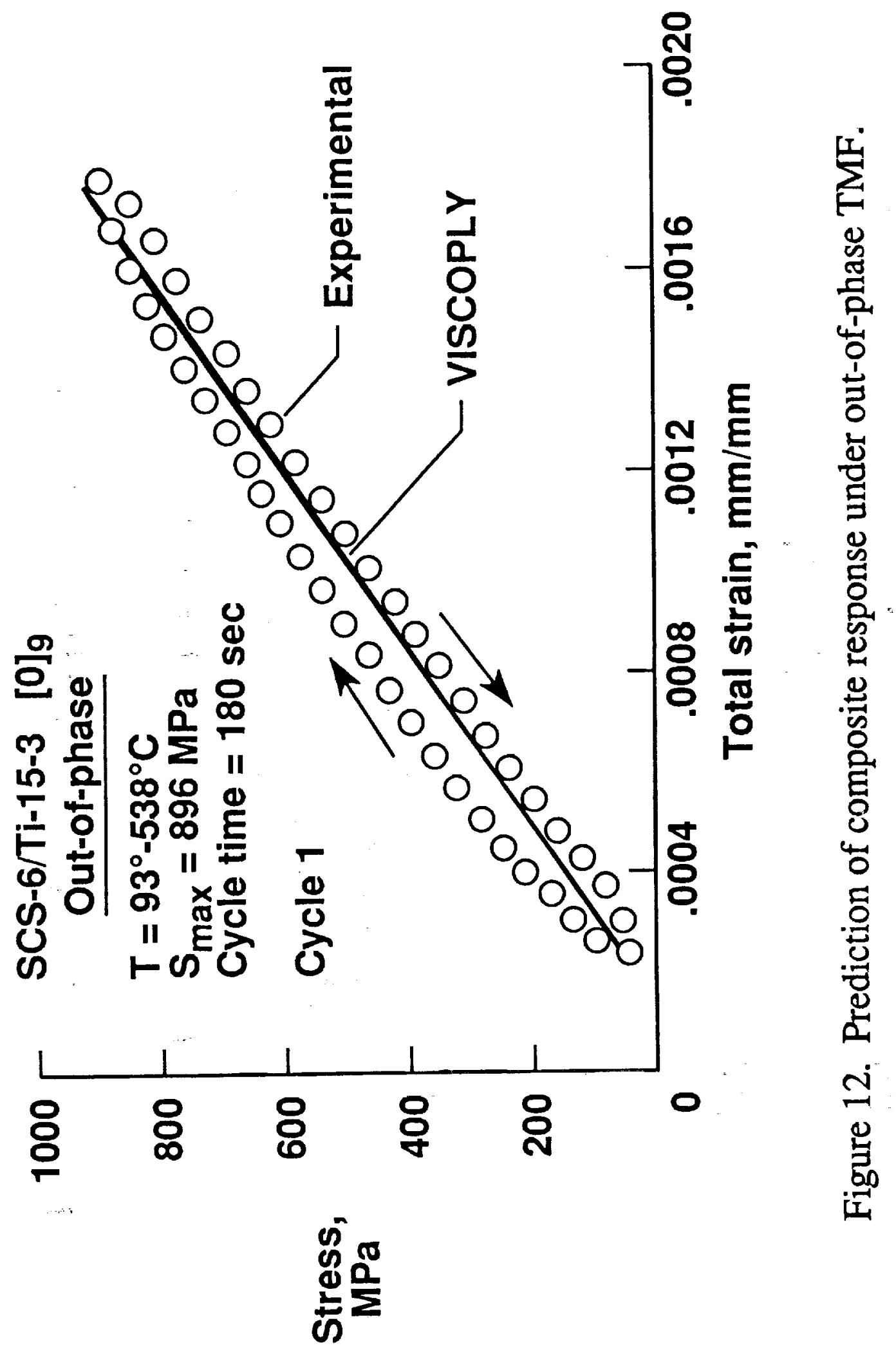




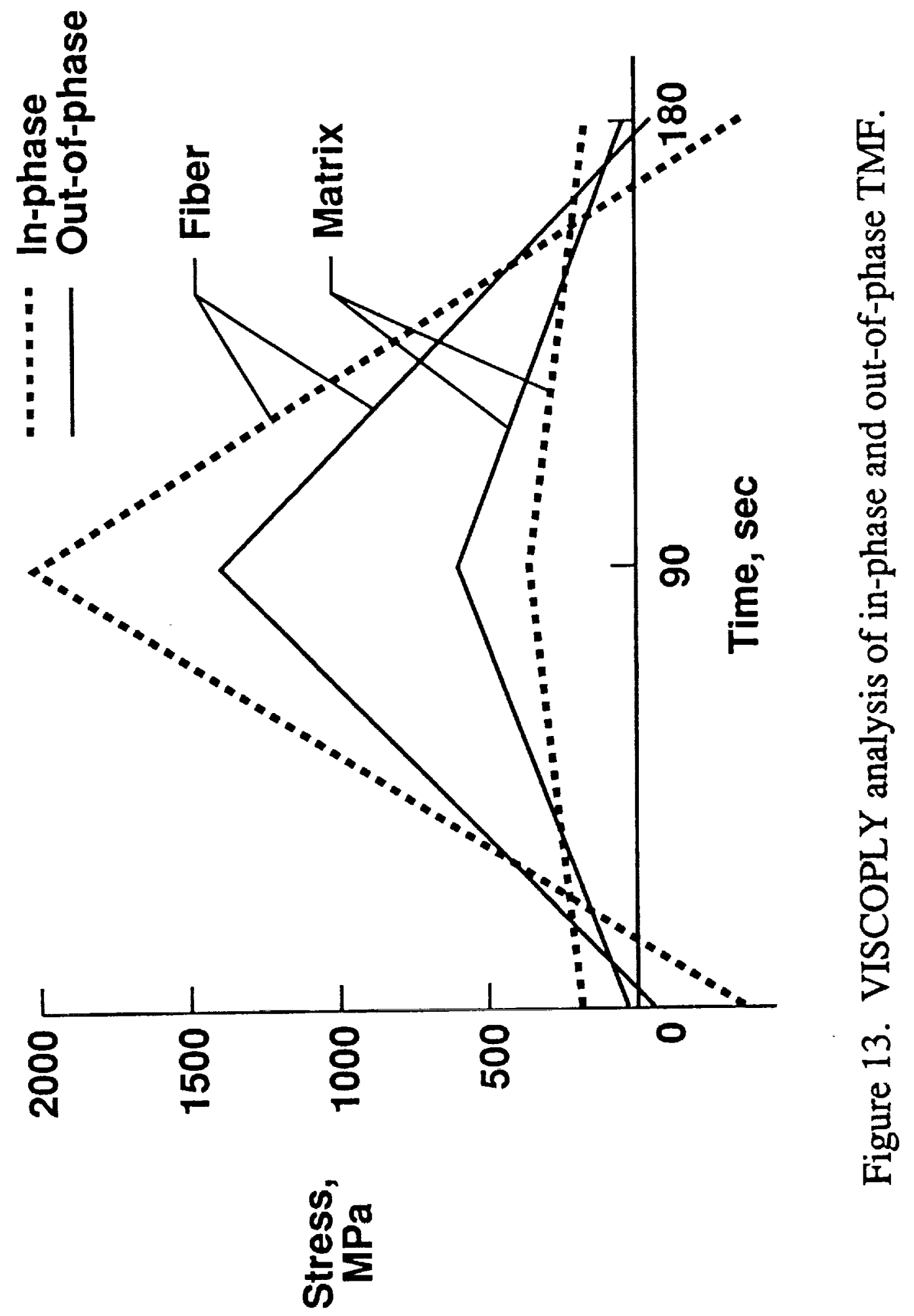




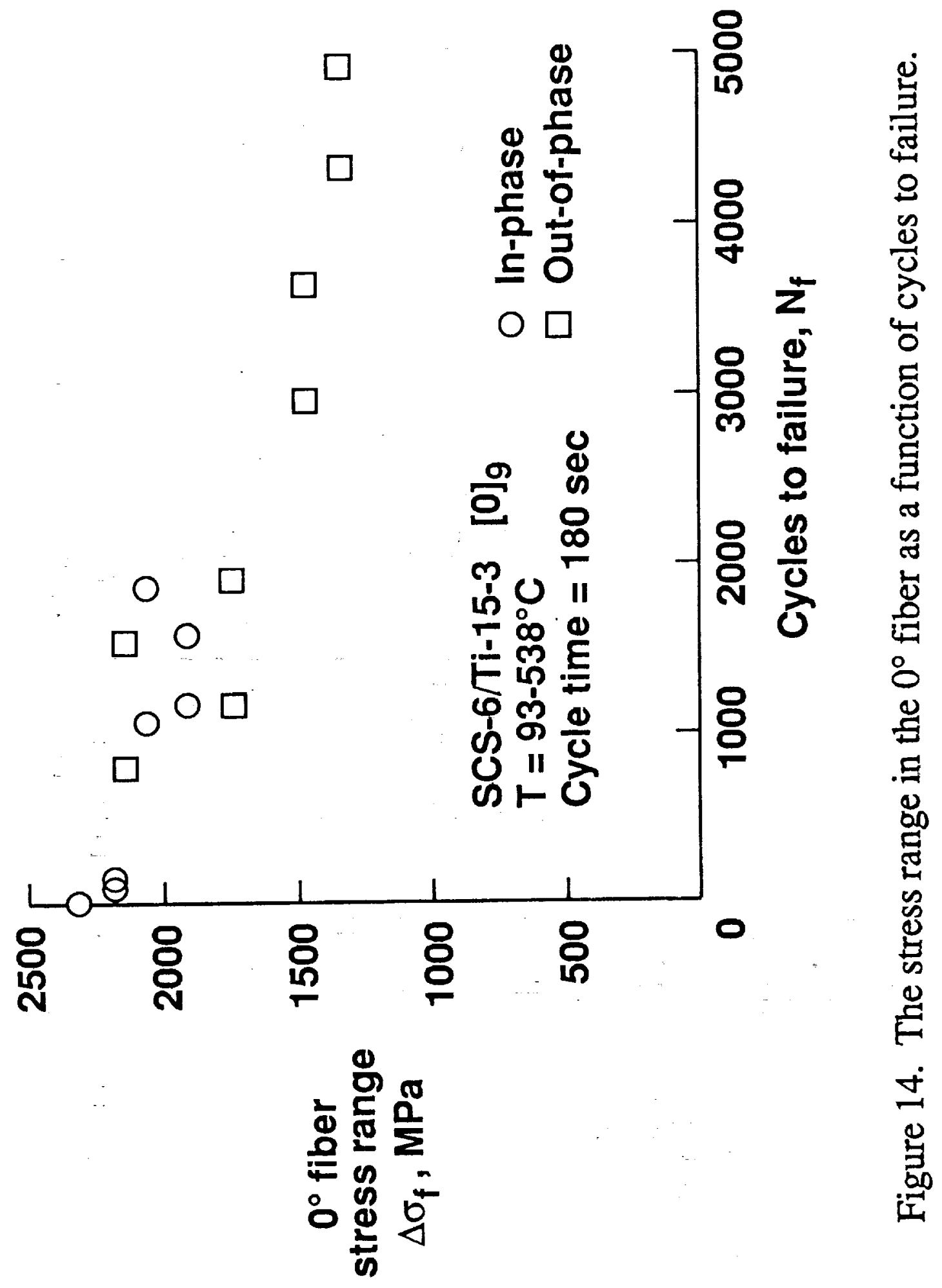




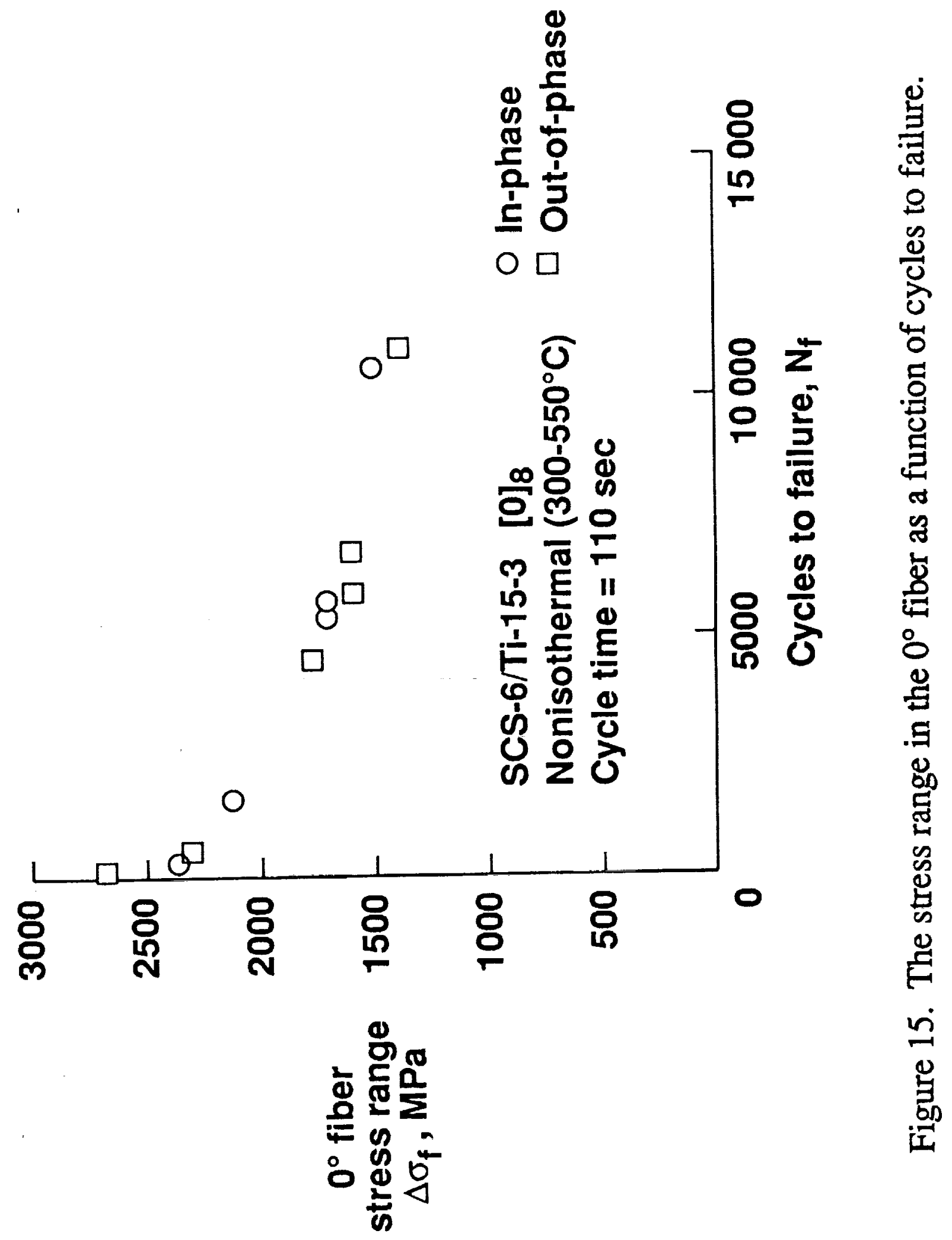




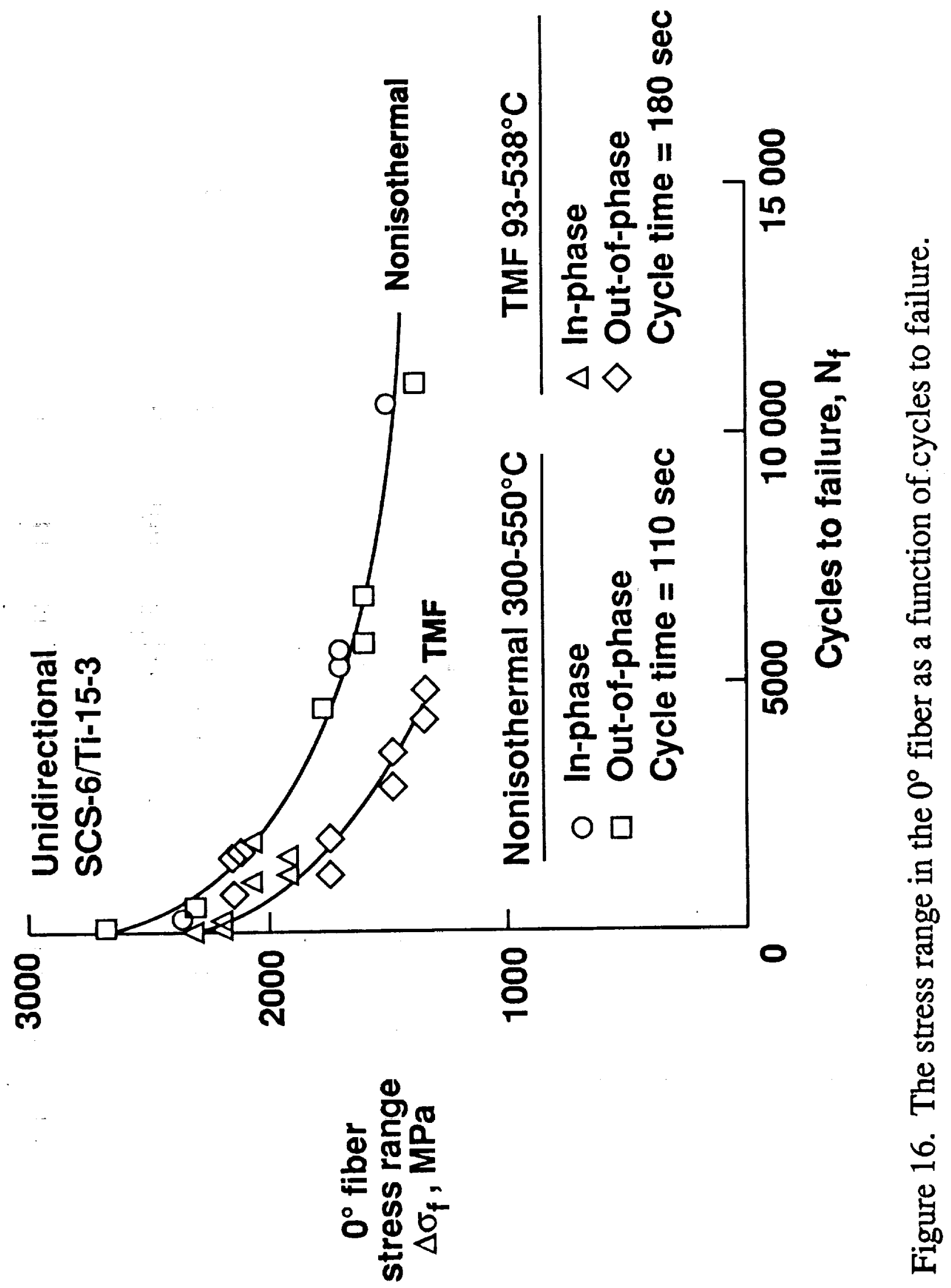




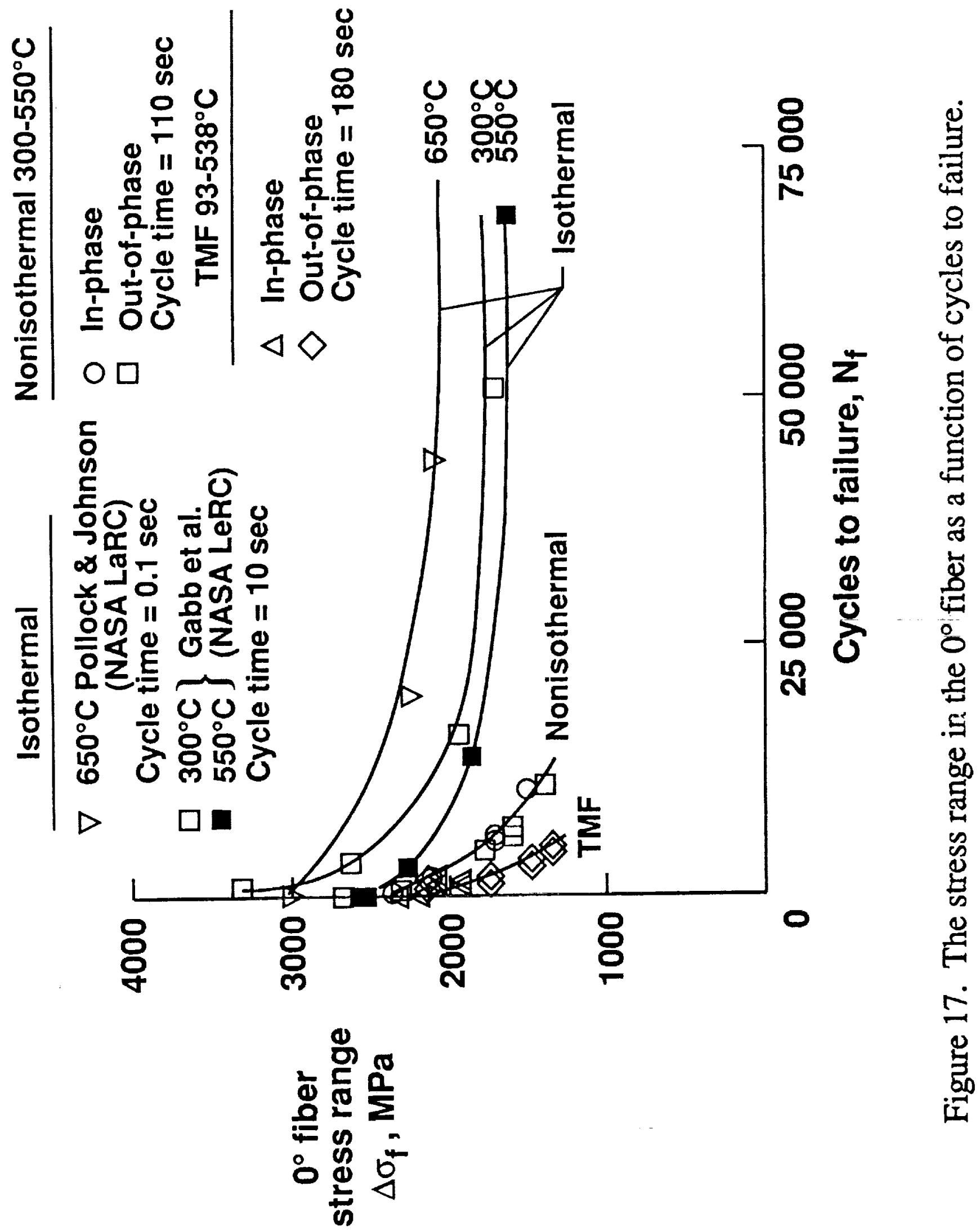




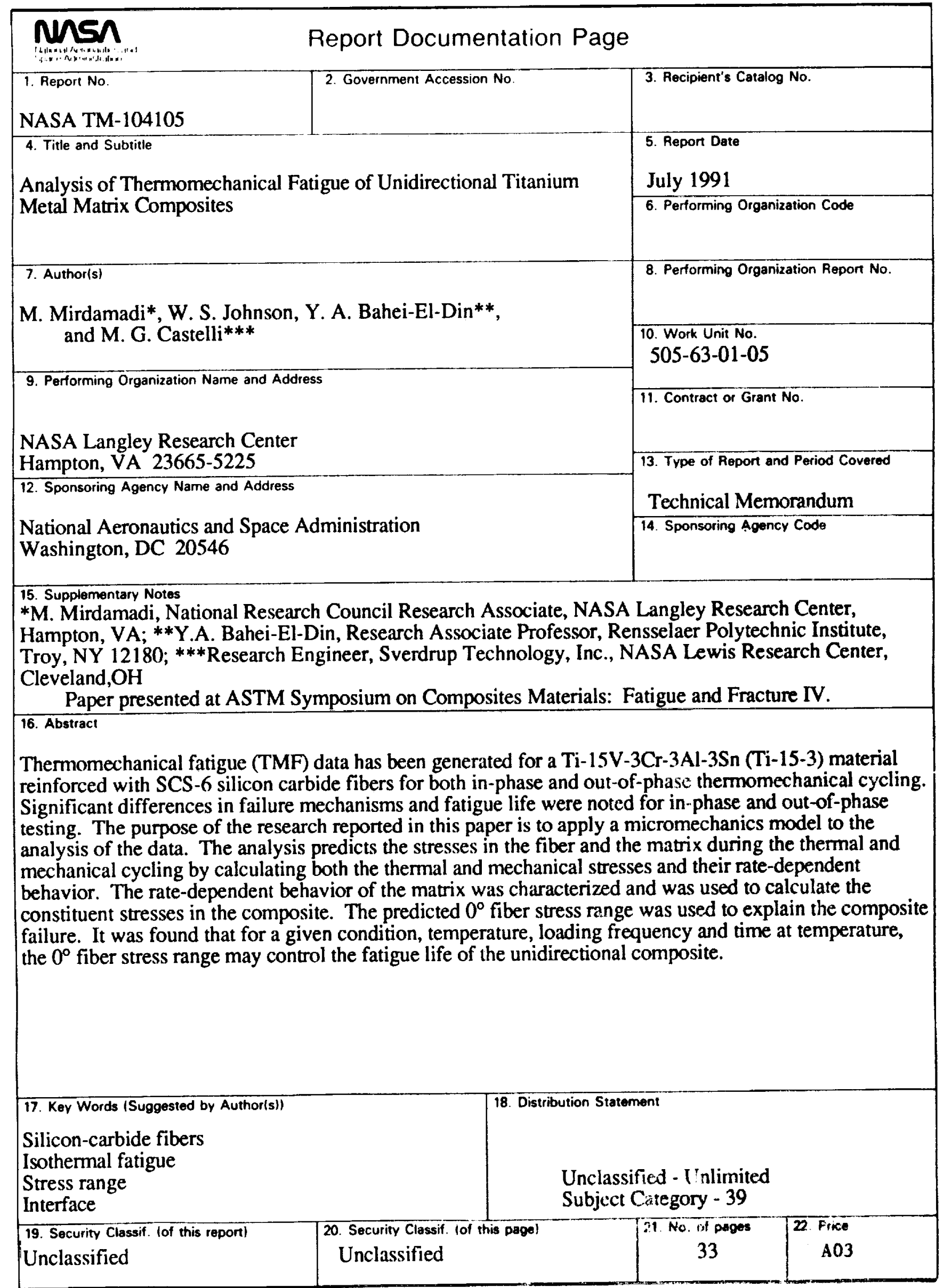


$\therefore-\therefore$

$\cdots \cdots$

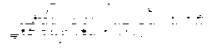

$-\quad-\quad+\cdots \div$

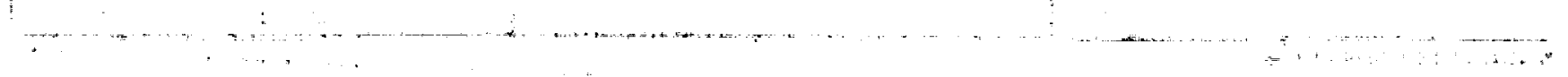

